\title{
Renal Homotransplantation:
}

\section{Late Function and Complications}

Thomas E. Starzl, PH.D., M.D., Thomas L. Marchioro, M.D., K. A. Porter, M.D., D.SC., C. A. Moore, LT. COL., MC, David Rifkind, PH.D., M.D., and William R. Waddell, M.D. Departments of Surgery and Medicine, University of Colorado School of Medicine, and the Denver Veterans Administration Hospital, Denver, Colorado.

In the earlier days of renal homotransplantation, the most important cause of failure was prompt rejection of the homograft. Except for a few tantalizing exceptions, most of the patients treated by this means died during the first few weeks after operation either from return of renal failure or as the result of drug toxicity induced during efforts to prevent repudiation of the homograft. Such tragically unsuccessful cases of the pioneering era constituted the largest portion of the compilation of world experience made in September, 1963, by Murray (1) and the other participants at the National Academy of Sciences transplantation conference in Washington, D. C.

From our own experience $(2,3)$ and from that of other investigators (4-8), a quite different view has emerged during the last 2 years concerning the potentialities of renal homotransplantation. Although rejection or drug toxicity, or both, are still important causes of acute postoperative mortality, three fourths of all patients treated at the University of Colorado Medical Center with homografts obtained from living donors have survived for longer than 2 months and considerably more than half are still alive on June 10, 1964, from $2 \frac{1}{2}$ to 18 months postoperative. It has been learned that rejection, when it occurs, can be reversed, even when it is of great severity $(2,5,7-11)$, that the degree of requisite immunosuppressive therapy usually diminishes late in the postoperative period, and that the successfully treated patients can resume life in a relatively unrestricted environment. Imperfect though they are, the techniques of surgery and early postoperative care, as they are practiced today, provide the recipient with a greatly improved outlook. With favorable combinations of consanguinity, such as those obtained with the use of sibling or parental donors, the prospects of surviving into a chronic stage approach acceptability (2-5).

In spite of these encouraging notes, the long-term value of renal homotransplantation in the treatment of terminal diseases of the kidney remains conjectural. Little is known of the projected fate of the homografts or of their recipients since only a handful of late cases have been reported.

This paper analyzes a large group of patients who lived for more than 4 months after operation and attempts to characterize those late problems that have already been encountered and that may become increasingly prominent with the further passage of time. Special attention will be focused upon the adequacy of late homograft function; the frequency, severity, diagnosis, and therapy of delayed rejection; the incidence and treatment of indolent mechanical urologic

Requests for reprints should be addressed to Thomas E. Starzl, M.D., Professor of Surgery, University of Colorado Medical Center, 4200 East Ninth Street, Denver, Colorado 80220.

Dr. Starzl is a Markle Scholar. Dr. Porter is a Reader in Pathology, St. Mary's Hospital and Medical School, London, England. 
complications; the long-term side effects of drug administration; and the possible role of thymectomy in favorably influencing the chronic course.

\section{MATERIAL AND METHODS CASE MATERIAL}

Fifty-one persons were treated 4 months or longer ago (Table 1). The operations took place in the interval between November 24, 1962, and February 10, 1964. Eighteen patients died in the first 4 months. Their courses, factors contributing to early success, and the causes for failure are described elsewhere $(2,3)$ and will not be considered here. The genetic relationships of the donors for the entire group of 51 cases are indicated in Table 1, and it will be noted that the preponderance of good results occurred when the donors and recipients were closely related. Thirty-three of the 51 patients lived for at least 4 months, and this residual group of longer survivors forms the basis for this report.

\section{IMMUNOSUPPRESSIVE MEASURES}

In 44 of the cases, initial therapy was provided with a single drug, azathioprine, started before operation and continued indefinitely. At the time of rejection, massive doses of prednisone (as much as $300 \mathrm{mg} /$ day) were added (Figure 1). In many cases actinomycin C (12) and local irradiation to the transplant site $(11,13,14)$ were intermittently used $(2,3)$. After reversal of rejection, the prednisone was reduced as promptly as possible to maintenance levels of 40 to $60 \mathrm{mg} /$ day and slower steroid withdrawal was then attempted in the ensuing weeks and months (Figure 1).

In seven cases, steroids were used prophylactically, beginning 1 to 3 days before operation in doses of 100 to $200 \mathrm{mg} /$ day of prednisone and continuing into the postoperative period (Figure 2). If rejection occurred with this regimen, it was treated with intravenous actinomycin $\mathrm{C}$ or local transplant irradiation, or both (Figure 2). Withdrawal of the steroids was carried out at approximately the same rate as in the other group and for this reason, both the early and later cases will be grouped together for purposes of subsequent discussion.

All 51 patients had splenectomy, usually at the same time as bilateral nephrectomy and renal homotransplantation, but occasionally in advance of the definitive operation. Justification for the use of this adjuvant procedure has been presented previously, although direct experimental evidence supporting its use has not been demonstrated either in our laboratories or elsewhere $(2,15)$. Eight of the first patients also had thymectomy from 13 to 85 days before transplantation (Table 1). The rationale for use of this operation is discussed in more detail below, since it is possible that some delayed benefit may accrued from its use.

\section{PROVISIONS FOR CHRONIC CARE}

If late complications are to be effectively treated, it is essential that they be diagnosed promptly. For this reason all patients are followed in two special transplantation clinics after discharge from the hospital. These clinics, which are staffed with internists, pediatricians, immunologists, and surgeons, have a relatively fixed personnel so that patients can be repeatedly examined by the same physicians. A special effort is made to obtain accurate blood pressure measurements and weight and to thoroughly evaluate as well any local features of the transplant site.

Hematologic studies and creatinine clearance determinations are performed by research laboratories so that greater dependence can be placed on small changes for the formulation of therapeutic policy. Ordinarily, follow-up visits are scheduled once a week for the first month or two after discharge, but subsequently the patients may be seen only once every 2 to 8 weeks. At this phase of convalescence they are often allowed to return to their homes, even if these are in distant cities, under the care of physicians who are carefully selected on the basis of their 
special interest in renal disease. Each patient is impressed with the necessity of immediately seeking medical care if fluid retention, oliguria, or transplant wound tenderness is noticed. Between clinic visits, no restrictions are placed on activity except for avoidance of contact sports such as football. They go to movies and other public gatherings. Virtually all those patients now living more than 4 months have returned to some kind of work or to school.

At each visit, blood urea nitrogen, creatinine clearance, hematocrit reading, white blood count and differential, urinalysis, and urine cultures are ordered. Frequently, intravenous pyelograms are obtained early in the postoperative course, and these are always performed after 3 months. If there is any equivocation about the normality of the ureteropelvic system, an intensification excretory urogram is obtained with a modification of Wilson's technique (16). A test dose of $50 \%$ sodium diatrizoate $\left(\text { Hypaque }{ }^{\circledR}\right)^{*}$ is given, followed by intravenous administration of 30 $\mathrm{ml}$ of the contrast material. An additional dose of $90 \mathrm{ml}$ is then given by continuous infusion over a 30-min period, during which time X-ray exposures are made, developed, and reviewed. Delayed films are also valuable in judging the rapidity of emptying. Using this method, good visualization of the collecting system can almost always be obtained and, in fact, cystoscopy and retrograde pyelography have been necessary on only one occasion.

In a number of cases, radioisotope renograms were obtained with the method of Winter (17), using sodium orthoiodohippurate- $\mathrm{I}^{131}$ (Hippuran- $\left.\mathrm{I}^{131}\right)(0.9 \mathrm{mc} / \mathrm{kg})$.

\section{RESULTS \\ MORTALITY AND SURVIVAL}

These data are presented in Table 2.

\section{MORTALITY AFTER 4 MONTHS}

Thirty-three of the first 51 patients lived longer than 4 months. Subsequently, three of these died.

In one case ( $L D 9$ ) death occurred 207 days after an emergency operation for control of bleeding duodenal ulcer (Figure 3). At autopsy, fungal brain abscesses and pneumonia were found. In this patient, whose donor was a fraternal twin (blood group direction $\mathrm{O}$ to $\mathrm{A}$ ), it had been necessary to use large maintenance doses of prednisone (30 to $60 \mathrm{mg} /$ day) in order to maintain stable renal function (Figure 3). In the last days of life there was deterioration of renal function that coincided with development of septicemia with Pseudomonas aeruginosa, Candida albicans and kruzei, and Nocardia asteroides.

Grossly, the transplanted kidney was slightly enlarged (180 g). The capsule stripped easily, and the subcapsular surface was smooth. On section, the cortex appeared pale and contrasted with a deep red medulla. The renal pelvis and ureter were normal with no evidence of stricture at any point. The main renal vessels and their anastomoses were free from thrombus or fibrous narrowing.

Microscopically, the glomeruli were hypertrophied and there was some periglomerular fibrosis but no other changes were seen in the tufts. Widespread and severe tubular atrophy was present (Figure 4) together with some birefringent calcium oxalate crystals. Recent tubular necrosis, casts, and calcification were not present. There was a very mild cellular infiltration consisting mainly of plasma cells with a few small lymphocytes and very occasional larger pyroninophilic lymphoid cells. Interstitial fibrosis was diffuse and prominent (Figure 4). There was no

\footnotetext{
*Manufactured by Winthrop Laboratories, New York 18, N. Y.
} 
hemorrhage. Scattered Candida hyphae and Nocardia were present with no surrounding cellular reaction. Many peritubular capillaries had been completely destroyed, but the arterioles and veins were normal. There was very slight fibrous intimal thickening affecting a few of the interlobular arteries.

The second patient ( $L D 20$ ), a 5-year-old boy of O blood type who received an A group maternal homograft, survived for 202 days. Two months before his death he suddenly developed convulsions and deep coma from which he never aroused. There was no evidence of late rejection. Permission for autopsy was denied.

A third patient ( $L D 10$ ), who died at 295 days of an uncontrolled late rejection, is considered in detail below.

\section{LATE REJECTION}

Evidence of delayed rejection was observed in 6 patients 4 months or longer after operation (Table 3). In one (LD 10), the process was not controlled. The patient, a 46-year-old man of $\mathrm{O}+$ blood type, received a homograft from a volunteer convict donor whose blood group was O-. Steroids were withdrawn unusually rapidly because of a series of early complications (Figure 5) including myocardial infarction, gastrointestinal hemorrhage, and aseptic necrosis of the first lumbar vertebra. Prednisone was discontinued 126 days after operation. After 103 days the blood urea nitrogen (BUN) began to rise (Figure 5). The homograft was locally irradiated with two doses of $150 \mathrm{r}$ at depth, 254 and 256 days postoperatively with a subsequent brisk diuresis and rapid fall of BUN. The improvement was short lived. Within 2 weeks progressive azotemia reappeared (Figure 5). Prednisone was restarted first in doses of $20 \mathrm{mg} /$ day and later with $200 \mathrm{mg} /$ day to which a course of intravenous actinomycin $\mathrm{C}$ was added. The progressive renal failure was not halted, and the patient died 295 days after homotransplantation. The last BUN was $165 \mathrm{mg} / 100 \mathrm{ml}$. Terminally, multiple pulmonary embolization occurred. The patient became hypertensive for the last 40 days of life with blood pressures in the 170/90 $\mathrm{mm} \mathrm{Hg}$ range.

Grossly, the homograft was greatly enlarged ( $260 \mathrm{~g})$. The capsule stripped easily, leaving a pale subcapsular surface speckled with a few tiny hemorrhages (Figure 6). On section, the cortex bulged. The renal pelvis, ureter, and the main renal vessels were normal and unobstructed.

Microscopically, the glomeruli were hypertrophied, and in some there was extension of fibrinoid necrosis from affected afferent arterioles into the tuft capillary loops (Figure 7). Periglomerular fibrosis was present in a few. Scarring of the tuft and loss of the glomeruli were not prominent features. The basement membrane of the tuft capillaries appeared normal, and there was no juxtaglomerular hyperplasia.

Many of the tubules were atrophic and lined by flattened epithelium, but there was evidence of continuing regeneration. A few of the proximal convoluted tubules showed acute necrosis, and these contained casts of protein.

In the interstitium there were focal collections of cells. This was not a heavy infiltration and consisted mainly of small lymphocytes, plasma cells, and lymphoid cells of various sizes but each with a large nucleus, prominent nucleolus, and pyroninophilic cytoplasm. Mitoses were not seen. There was widespread fibrosis and some edema.

There was fibrinoid necrosis of the walls of some afferent arterioles and interlobular arteries, and adjacent to some of these necrotic lesions were local interstitial hemorrhages. In some 
interlobular arteries there were deposits of fibrin and platelets on the damaged intima. Other arteries showed marked narrowing of their lumens by fibrous intimal thickening (Figure 7).

Five other patients (LD 12, 13, 22, 23, and 30) had more or less clearly documented late rejection occurring 112 to 300 days after operation (Table 3 ). The homografts in these cases were obtained from nonrelated donors in two (Figures 8 and 9), a sibling in one (Figure 10), and from mothers in two (Figure 11). The events preceding rejection were similar to those in the patient described above. Good renal function had been maintained despite progressive attenuation or complete discontinuance of the steroid therapy. Sixteen to 154 days after stopping the steroids (Figures 8, 10, and 11) or dropping the dose to below $45 \mathrm{mg} / \mathrm{day}$ (Figure 9) declines in creatinine clearance were noted, usually before any change had occurred in the BUN. In one asymptomatic patient, the decline of routinely determined creatinine clearance was the only finding (Figure 11). Orthostatic ankle edema was noticed by others late in the day. Rapid loss of hair, low-grade fever, malaise, joint pains, and loss of appetite were all observed in more than one but not in all the cases. A sense of fullness and slight tenderness in the transplant site enabled two patients to suspect the diagnosis.

\section{DIFFERENTIAL DIAGNOSIS OF LATE REJECTION}

The diagnosis of late rejection must be made by exclusion of other causes for late renal failure including chronic pyelonephritis, occlusion of the arterial anastomosis, and ureteral obstruction. Examination of the tissues after needle biopsy has not been done because of the potential risks. Instead, the principal emphasis is on detection of mechanical or infectious complications that are correctable. Failing to find these, vigorous antirejection measures are instituted.

The physical findings of late rejection have been almost pathognomonic, especially if careful examination was conducted and recorded by the same physician during preceding follow-up visits. The homograft that may have been nontender and almost impalpable became painful and prominent in each case. Slight local edema of the transplant wound was seen in addition to the collection of fluid in the lower extremities. Usually these changes evolved over a period of several days or even weeks. Blood pressure rises above those previously recorded were present in all but one of the six cases. Three of the six patients developed low-grade fever.

The renal failure of delayed rejection was desultory in comparison to that which occurs in the immediate postoperative period (Figures 7-11), a fact that added to the difficulty of establishing a certain diagnosis, but that also made practical the systematic employment of certain procedures before subjecting the patient to an intensified course of immunosuppressive therapy. Multiple urine cultures were immediately obtained. Urine electrolytes were determined. A falling sodium concentration has the same diagnostic significance as with an acute rejection episode (2). The demonstration of increased proteinuria strongly supports the diagnosis of rejection (7).

If rejection was suspected because of declines in renal function or because of the other symptoms or findings described above, the first special examination was often a radioisotope renogram using sodium orthoiodohippurate- $\mathrm{I}^{131}$ as suggested by Collins and his associates (18). Inferential information concerning the renal circulation can be quickly obtained in this way. If a sharp vascular phase is demonstrated, the likelihood of vascular failure is greatly decreased. It has not been found necessary to perform dye arteriography in any case, and no occlusive lesions have been found.

The radioisotope renogram is of limited value, however, in differentiating rejections from ureteral obstructions. Similar curves have been obtained in both situations. Poor excretion of the dye has been observed in a patient (LD 30) who had been shown by intravenous pyelography 
3 weeks previously to have normal ureteropelvic drainage. Increased immunosuppressive treatment caused reversion of the curve to normal. The immediate improvement in function which followed augmentation of antirejection therapy suggested that the delayed excretion may have been due to interstitial edema and compression of the intrarenal collecting system. Almost identical curves have been seen in a case (LD 27) in which the cause was later proved to be due to a midureteric stricture that required surgical repair.

Because the loss of renal function is gradual, pyelographic visualization of the extrarenal collecting system is usually possible if a re-inforcing dye dose of contrast material is given. The demonstration of a normally draining ureter and pelvis greatly strengthens the possibility that rejection was a cause of the diminished excretory capacity. If dye concentration is not obtained, retrograde visualization should be attempted since several partial ureteral blocks have been encountered, as will be described in the ensuing section.

\section{LATE UROLOGIC COMPLICATIONS}

The few examples of late urologic complications after transplantation have been reported although it is known that one of Murray's identical twin recipients has developed renal stones (19), and that one of the patients in the St. Mary's Hospital series developed urinary extravasation more than 100 days after transplantation (20).

In the present series of patients, late ureteric obstruction was seen on four occasions. In three of these, the stenosis was asymptomatic, being detected by routine intravenous pyelography. In these three, the narrowed area was at the site of implantation into the bladder (Figure 12). The obstructive uropathy was relieved in each case by re-operation and performance of anastomosis of the pelvis or ureteropelvic junction to the patient's own ipsilateral or contralateral ureter. The utility of this type of procedure in treating complications at the bladder implantation site emphasizes the advisability of not performing ureterectomy except for specific indications at the time the patient's own diseased kidneys are excised.

In the fourth patient ( $L D 27$ ), the cause of the obstructive uropathy could not be readily classified, and this case will be described separately because of the possibility that this represented a late complication of a previous rejection. A 21-year-old woman received a homograft from a convict donor on September 3, 1963. There was only equivocal evidence of early rejection after which she had stable renal function until March 18, 1964, by which time her prednisone dose had been reduced to $10 \mathrm{mg} /$ day. After a severe bout of diarrhea induced by castor oil, anuria developed that lasted for 5 days.

Emergency antirejection measures were taken with high doses of steroids, actinomycin C, and two courses (total, $900 \mathrm{r}$ ) of local irradiation. During the next several weeks, anuria or oliguria alternated with diuresis (Figure 13). An intravenous pyelogram obtained during a diuretic phase showed obstruction high in the ureter (Figure 14). Ultimately, she was treated with anastomosis of the proximal homografted ureter to the distal portion of her own ipsilateral ureter on April 18, 1964. Recovery was uncomplicated (Figure 14).

That portion of the midureter that was removed at the time of re-operation had a high-grade internal stricture extending over at least $1 \mathrm{in.}$ Microscopically, there was severe fibrous thickening of the intima and rupture of the internal elastic lamina of the majority of the arteries in the wall of the affected segment. In addition, there was much muscle necrosis, a heavy cellular infiltration and virus inclusion bodies. This case and several others in which ureteric and pelvic lesions were seen are considered in detail in another communication and their relationship to previous rejection episodes discussed (21). 


\section{TREATMENT OF DELAYED REJECTION}

The same therapy is effective as that previously described for reversal of rejection occurring early in the postoperative period $(2,5,7,9-12,14)$. The slow development of delayed rejections observed in the present series made it possible in some instances to evaluate the effect of individual agents. Thus, local transplant irradiation (Figures 5 and 9) and increased dosages of steroids (Figure 11) were both shown to be of therapeutic value when used alone in one or more isolated cases.

However, in one patient (LD 10) in which these agents were used serially, remittent deterioration continued until the secondary renal failure became irreversible despite the fact that urine excretion was never less than 1,000 ml/day. Although the homograft had serious histologic abnormalities (Figure 7), some of the findings were probably reversible, including the intestinal edema, had more vigorous immunosuppressive measures been taken at once. Because of the fatal outcome in this case, the subsequent patients were treated much more aggressively, adding agents more quickly and sometimes in combinations (Figures 8 and 10).

An idea of the relative roles of the various immunosuppressive agents in the treatment of late rejection can be obtained from a review of those events that invariably preceded the onset of this serious complication. Since a maximum safe dose of azathioprine had been used in all these cases, with only minor variations in daily quantity, the inefficient administration of this drug did not seem to be a factor in the initiation of delayed rejection. Furthermore, the previous employment of this agent to those limits that were compatible with safety of the host made further increases in dosage impractical.

In contrast, it appeared as if stability of homograft function was disrupted in every one of these cases, either by discontinuance of prednisone or by reduction of this drug to a lower level than had previously been used for some time. Thus, steroids had been stopped for Patients LD 10, $12,13,22$, and 23 . Rejection was recognized $103,154,20,60$, and 16 days later, respectively. Patient LD 30 began to reject 30 days after reduction of prednisone from 45 to $30 \mathrm{mg} / \mathrm{day}$.

Because of the apparent dependence upon continued steroids for stable homograft function in such cases, the most important immediate alteration was thought to be prompt resumption of prednisone administration or an immediate dose increase for those patients who were already receiving slowly diminishing steroid maintenance. The extent to which the steroids must be employed in the treatment of late rejection is not known with any degree of certainty. In view of the fatal outcome of the one case in which small doses were first tried (Figures 5), three of the subsequent cases were treated with drastic increases (Figures 8, 10, and 11), which were continued until unequivocal evidence of an improvement in function had been sustained for several weeks. The most important objective measurement of excretory capacity was creatinine clearance since misleading elevations in BUN persisted despite improvement in other measures of function, apparently because of steroid-induced increases in catabolism.

Later, when clear evidence of reversal had been obtained, the steroid doses were slowly reduced (Figures 8 and 11). The success with which return to small daily doses can be achieved is yet to be determined, although it seems likely that continuation of prednisone in doses of 20 to 40 $\mathrm{mg} / \mathrm{day}$ will be required for many months and possibly even for the remainder of the patient's life.

Additional promptly directed immunosuppressive therapy was used at the time of late rejection, particularly when a diagnosis was not made early and when the degree of renal impairment was more than slight. Actinomycin $\mathrm{C}$ and repetitive local irradiation of the homograft (Figures 8 to 10) were used in the same way as has been previously described for the treatment of early rejection crises, X-ray therapy $(11,13,14)$ being of the greatest immediate value. After the 
first application of $150 \mathrm{r}$, the sense of fullness or pain over the transplantation site was immediately relieved in every case. Reduction in the size of the homograft was noted by palpation.

Although the value of these adjuvant immunosuppressive procedures, especially local irradiation, seems real, they should not be used as the sole adjustment of treatment for several reasons. Although temporary improvement in renal function can be expected, it occurs against the background of that therapy that has already proved to be insufficient. Furthermore, the chronic use of the added agents, which would presumably be necessary if steroid therapy were not intensified, has serious disadvantages since actinomycin $\mathrm{C}$, which is probably only of moderate effectiveness in any event, has important systemic toxicity that makes its protracted use undesirable (2). Alternatively, repeated courses of local X ray would involve the risk of producing irradiation injury to the homograft. The use of local transplant irradiation and actinomycin $\mathrm{C}$ should, therefore, be viewed as temporizing during an emergency and should coincide with the definitive alteration in steroid management.

\section{LATE RENAL FUNCTION}

Adequate, if not normal, renal function was obtained from virtually all homografts that were still functioning after 4 months. The last creatinine clearance and BUN's are listed in Table 1 for each patient in the series who lived for more than 4 months. The lowest creatinine clearance in any of the patients still alive in June, 1964, was $27 \mathrm{ml} / \mathrm{min}$ (LD 41, a 3-year-old child), and the highest BUN was $54 \mathrm{mg} / 100 \mathrm{ml}$ (LD 30). The mean values for the 30 cases still being followed were $88.1 \mathrm{ml} / \mathrm{min}$ for creatinine clearance, and $23.7 \mathrm{mg} / 100 \mathrm{ml}$ (BUN). Although these figures are important in making clear the fact that generally good homograft function can be obtained, it should be again emphasized that trends in function are of greater prognostic significance than any individual determination. Thus, a patient whose creatinine clearance has dropped from 100 to $70 \mathrm{ml} / \mathrm{min}$ may pose a far more serious problem of late management than another who has a stable creatinine clearance of $50 \mathrm{ml} / \mathrm{min}$.

In those patients followed for the longest times in whom delayed rejection has not adversely affected the late course, the function has tended to improve with the passage of time (Figures 1 and 15) so that functional hypertrophy in the recipient has been almost parallel with that of the donor. Thus, in Patients LD 1, 2, and 3, the creatinine clearances 4 months or longer after operation were $83,91.8$, and $129 \mathrm{ml} / \mathrm{min}$, respectively. Simultaneous determinations in the three respective donors were 112, 89.9, and $129 \mathrm{ml} / \mathrm{min}$. Prior to delayed rejection and 146 days after operation, the comparative creatinine clearances in LD 12 were $70.5 \mathrm{ml}$ for the donor and $73.3 \mathrm{ml} / \mathrm{min}$ for the recipient. The tests have not been repeated since reversal of the subsequent delayed rejection shown in Figure 10.

\section{LATE BLOOD PRESSURE}

In a previous publication, emphasis was placed upon the cyclic appearance of hypertension that was often a troublesome problem during rejection and that tended to recede after reversal of this process (9). Since care was exercised to maintain normal or near normal blood pressures during early convalescence, most patients were placed on one or more antihypertensive drugs during this period. The ultimate blood pressure in these patients, and the need for later continuation of such pharmacologic agents assumes an especial importance because of the vascular lesions that have been found in many homografts studied by needle biopsy or at autopsy $(20,22,23)$.

Except in those cases in which late convalescence was marred by delayed rejection, the tendency to hypertension and the re quirements for antihypertensive drugs was less with the passage of time (Table 1) and seemed to be directly related to the level of maintenance steroid 
therapy required for protection of the homograft. The average sitting blood pressures during May, 1964, are given for all patients in the present series in Table 1 as well as an account of the antihypertensive drugs being used during this time. It will be noted that none of the patients followed for the longest intervals are receiving any medication of this type.

\section{LATE DRUG TOXICITY}

Overt evidence of late azathioprine toxicity has not been encountered, although two patients (LD 15 and 36) have developed hepatitis 6 and 3 months, respectively, after operation, which was thought to be of viral etiology. It is possible, however, that this may be a manifestation of specific drug toxicity as Murray (7) has suggested. A high incidence of hepatotoxicity has been reported by McIlvanie and McCarthy (24) and by Einhorn and Davidsohn (25) after chronic administration of the related agent 6-mercaptopurine to patients with leukemia.

The consequences of protracted steroid administration have seemed to be much more serious. The high incidence of gastrointestinal hemorrhage during steroid administration in the early postoperative period was previously described (26). In those cases followed for more than 4 months, there have been two additional examples (LD 9 and 30) and in one of these, bleeding was an important contributory cause of death (Figure 3). Radiographic evidence of severe osteoporosis has been noted in many patients, and in one aseptic necrosis of the first lumbar vertebra was detected 3 months after operation (27). In two other young adolescent females

(LD 22 and 50), aseptic necrosis of the femoral head (Figure 16) occurred $5 \frac{1}{2}$ months and 5 months after operation, respectively. The prednisone doses at the time of these complications were 10 and $30 \mathrm{mg} /$ day, respectively.

Immediately after transplantation, remarkable increases in body weight often occur due to an enormous caloric intake. In some of the patients in whom it has been impossible to reduce prednisone below 20 to $30 \mathrm{mg} /$ day, appetites have continued to be insatiable, and obesity has followed almost to the degree seen in the Pickwickian syndrome. Both the aforementioned girls with aseptic necrosis of the femoral head developed this complication only after gains of $10.6 \mathrm{~kg}$ and $11.5 \mathrm{~kg}$ over their preoperative weight.

\section{DISCUSSION}

It has been noted by many authors that the necessary intensity of immunosuppressive treatment can usually be relaxed after the critical first 1 to 3 postoperative months. If this were not the case, there would be no hope for the useful clinical application of homografting procedures since the long-term use of maximum therapy results in immunologic crippling and death from complications of the agents employed.

Although some degree of host-graft adaptation $(2,3,9,28-31)$ seems to be common to almost all renal homotransplantations, the completeness of this change in clinical cases is not known. It is conceivable that the apparently well-tolerated homograft is under constant but imperceptible attack and that it will be slowly rejected over a period of months or years. The underlying mechanism may be a gradual destruction of peritubular capillaries by infiltrating cells resulting in foci of tubular atrophy and interstitial fibrosis. Certainly these changes were present in the two homotransplants from the present series, which were examined at 207 and 295 days, and they have featured prominently in the published descriptions of other renal homotransplants, both human and dog, that have failed late. In addition, even without overt acute rejection episodes, fibrinoid necrotic vascular lesions may occur and if these involve the interlobular arteries they may lead to permanent narrowing of some of these vessels by fibrous intimal thickening $(20,22)$ as in Patient LD 10. Progressive ischemia may then become an important feature in limiting the functional life of the transplant. 


\section{PROLONGED SURVIVAL AFTER HOMOTRANSPLANTATION}

In these reported cases followed for the longest time, justification can be found either for a sense of futility or of hope. The first chronically successful renal homotransplantation was performed by Dr. Joseph Murray at the Peter Bent Brigham Hospital in Boston more than 5 years ago. Total body irradiation was the primary means of immunosuppression. Other subsequent measures to control rejection in this case were reported by Merrill and associates (32) in 1960. The patient, whose donor was a fraternal twin, was alive in May, 1964, with normal renal function. Murray (33) in a personal communication reported the results of a recent complete evaluation of the case as follows:

"A dizygotic twin of $5 \frac{1}{2}$ years recently left the hospital after a check-up including a biopsy. He is perfectly normal in every way as far as renal function is concerned. There are some microscopic changes which you can't really interpret, not knowing whether they are scarring as a result of his abortive rejection crisis of 5 years ago or whether it is some new very slow drain on the kidney. However, if we hadn't done the biopsy, we would consider him perfectly normal in every other way."

Although it may be true, as has been suggested by Goodwin and Martin (34), that some degree of natural chimerism may have existed in the foregoing case because of cross-placental circulation, there seems to be little reason to doubt that the homograft passed through a very mild stage of immunologic insult. Histologic evidence of cellular rejection was present on an open biopsy specimen obtained 9 months after the original operation.

The only other homografts that had maintained life for more than 2 years at the time of the Washington transplantation conference in September, 1963, were reported by Antoine and Hamburger (35) and by Shackman and Dempster $(13,36)$ and their associates. As with Murray's case, primary immunosuppressive therapy was with total body irradiation. In Hamburger's patient, who was operated upon a few months after Murray's, the kidney was also donated by a fraternal twin. By personal communication from Hamburger (37) it was learned that the patient was still in good health in May, 1964.

The patient treated by Shackman, Dempster, and Wrong (13), who was $2 \frac{1}{2}$ years postoperative in the fall of 1963, is of the utmost interest since he is the longest surviving human after homotransplantation between a nontwin donor and recipient. The patient who was receiving virtually no immunosuppressive therapy had only fair renal function (creatinine clearance, less than $25 \mathrm{ml} / \mathrm{min}$ ), but there has been no recent tendency to deterioration. In a follow-up on May 8, 1964, Dempster (38) has informed us that the patient is still in good condition, now 3 years and 2 months after operation.

These three patients with exceptionally prolonged survival have either not been subject to overt late rejection or if this has occurred, it has been mild and relatively easily controlled. These facts may give a misleading impression of the late expectation of other patients who have been treated with homotransplantation. The donor-recipient relationship in this small group of cases was highly favorable. The homografts were provided by fraternal twins in two instances and by a nontwin sibling in the third, groupings that greatly magnify the chances of matching the antigenic constitution of the donor and host. Furthermore, these remaining patients are quite obviously the further refined product of a sensitive biologic test system that ruthlessly weeded out all but those who fortuitously received the most genetically suitable homografts. The absence or mildness of late rejection in these valuable early cases is encouraging. It does not mean that delayed rejection will be a comparably trivial problem when the larger numbers of patients now receiving better early immunosuppressive treatment are brought to a similar chronic stage. 


\section{DELAYED REJECTION OF HOMOTRANSPLANTS}

Indeed, there is sound reason to avoid overoptimism at this time. Delayed rejection has been reported long after operation, usually manifesting a gradual decline of renal function over many weeks or months $(39,40)$ just as has been described in the present report. Woodruff and Robson (40), in a personal communication, have described two of the most disturbing examples in which fatal rejections occurred 15 and 16 months after two parent-to-offspring homotransplantations. In the most completely documented example of late rejection in the literature, Küss and associates (39) in 1962 described the same events in a patient who died 17 months after transplantation with progressive renal failure that was first recognized 9 months postoperatively. In this case it is of interest that a needle biopsy 59 days after homotransplantation already showed interstitial edema and proliferative vascular changes, the latter vascular changes having been observed by other authors $(20,23,41)$ at an even earlier postoperative time.

In spite of the dearth of information concerning late rejection, it is known that this problem has been encountered in other centers. Hamburger, Crosnier, and Dormont (5) have allowed us to read a manuscript that will appear in the Annals of the New York Academy of Science in 1964, in which he describes several variants of delayed homograft disease. These include two examples of acute rejection crises similar to those commonly observed in the early postoperative period, one at 6 and the other at 10 months. Biopsy in both revealed interstitial edema and cellular infiltration, but interstitial fibrosis was not mentioned. The process was reversed in both cases. In another of Hamburger's patients, who died of slow rejection after 22 months, severe interstitial fibrosis was present.

\section{GLOMERULONEPHRITIS IN THE TRANSPLANTED KIDNEY}

Hamburger and associates (5) have also drawn attention to the late development of chronic glomerulonephritis in the homograft, a complication that led to the death of one of his patients after 23 months. Although Murray, Merrill, and Harrison (42) had observed this in a patient with an identical twin isograft, it had not previously been seen after true homografting procedures except in cases reviewed from the St. Mary's series (20), and in a case reported by Krieg and associates (43). It is of great interest that glomerulonephritis was also seen by Hamburger after transplantation to a patient whose original disease was congenital interstitial nephropathy, a surprising sequence also reported by Krieg and associates (43) to have developed within a few days in a patient who had originally had pyelonephritis. Whether this "glomerulonephritis" observed in homografts has the same pathogenesis as that disease commonly seen in clinical practice, or is some variant of rejection, remains to be clarified.

\section{LATE OBSTRUCTIVE UROPATHY}

It has become increasingly clear that life-threatening problems other than rejection will also have to be detected and effectively treated if the residual population of homotransplanted patients is to be maintained and that ureteral obstruction may prove to be amongst the foremost of these. Four of the 33 patients in the present series who lived for 4 months or longer developed hydronephrosis. Although reconstructive procedures were possible in each, the necessary secondary operations were formidable ones and can be expected to carry a high risk. One of these 4 patients (LD 44) has a chronic partial urinary fistula after repair will probably require an additional reconstructive procedure. In some patients the ureteric block may prove to be due to healing of previous ureteric rejection as seems to have definitely occurred in one case (LD 27) of the present series. Similar late ureteric damage without obstruction was noted in a patient of Küss and associates (11) who died after 490 days. 


\section{TOXICITY OF DRUGS}

In addition, more information is needed concerning the toxicity of those drugs that are being administered. Perhaps it is natural to focus undue attention on the function and well-being of the homograft, sometimes almost to the exclusion of the beneficiary of this unnatural gift. In order to retain viability of the transplant, alterations in the host are inevitable. Some of these are obvious, others are subtle but measurable, but most of the changes are probably not even yet known. The ultimate toxicity of azathioprine, for example, in terms of a possible increased incidence of blood dyscrasias will take years to determine. The influence of this drug on reproductive physiology requires additional study. One of the male patients (LD 6) in the present series recently became the father of a normal child, which was conceived during the postoperative period of azathioprine therapy. Unpublished experimental studies by Dr. John A. Githens (44) of the University of Colorado Department of Pediatrics indicate that spermatogenesis is not seriously disturbed by this drug, but that its chronic administration to females induces a high incidence of anomalies in the offspring.

In the presently reported series, the chronic use of azathioprine has not by itself seemed to cause unacceptable toxicity in the late stages of recovery. Those patients now receiving only azathioprine enjoy a remarkably good state of health, most being 1 year or longer after operation (Table 1). That late toxicity from the mercaptopurine drugs is to be feared, however, is illustrated by one of Küss and associates' cases (45) in which fatal agranulocytosis abruptly terminated the course of an otherwise succesfully treated patient after 18 months.

Although relatively chronic therapy with azathioprine carries an apparently acceptable risk, the superimposition of large steroid doses can be said, even now, to add a significant element of morbidity. As was described, one patient receiving this combination required emergency surgery for control of bleeding duodenal ulcer and was also found at subsequent autopsy to have fungal brain abscesses (LD 9). Three patients with aseptic bone necrosis and the frightening prospect of massive obesity in others add to the timorousness with which the steroids have been continued.

In small children, the continuous use of large doses of steroids has in some respects an especially ominous significance. The alarming weight gains already described can be lifethreatening because of mechanical respiratory embarrassment. Bone growth may be limited or arrested if it is impossible to make substantial early reductions in dosage. Fortunately, the three youngest patients who are still alive have either had prednisone discontinued (LD 1) or reduced to $5 \mathrm{mg} /$ day (LD 34 and 41). Nevertheless, the last two patients still have residual evidence of hypercorticism.

\section{LATE "HOMOTRANSPLANTATION DISEASE"}

Finally, it seems important that certain other poorly understood manifestations of late "homotransplantation disease" be clarified. Recently a late febrile syndrome was described, accompanying steroid withdrawal (2), during which a peculiar and life-threatening pneumonic process was frequently observed (46). The cause of this late febrile syndrome is not known, but it may be a variant of the "late extrarenal syndrome" described by Hamburger, Crosnier, and Dormont (5). Several of their patients developed delayed fever, splenomegaly, hepatic dysfunction, and hypergammaglobulinemia. Hamburger has suggested that these findings may due to the establishment of an imperfect chronic equilibrium between the host and the homotransplanted kidney.

This detailed analysis of the late problems after renal homotransplantation has not been undertaken with any sense of pessimism or as an attempt to dampen the enthusiasm for those accomplishments that are already a part of recent history. It is clear that a remarkable change 
in the early postoperative outlook after homotransplantation has taken place at several institutions during the last 2 years. By personal communication in May, 1964, it was learned that Murray (33), Hamburger (37), Hume (47), and Kolff (48) all had a half dozen or more patients living essentially normal lives more than 6 months postoperatively. Of the first 64 patients at the University of Colorado Medical Center treated from November 24, 1962, to March 30, 1964, with homografts obtained from living donors, 47, or 74.4\%, survived for more than 2 months, and of this group 40 , or $62.5 \%$, were still alive on June 10,1964 . Thirty of these surviving patients were more than 4 months postoperative on this date, 25 were more than 6 months, and 5 were more than 1 year. Thus, the first hurdle of the transplantation problem has been at least partially breached in that a state of relatively protracted homograft function can be attained in considerably more than half the cases.

With this change has come a shift in responsibility for those institutions performing clinical investigation in renal homotransplantation. A change in emphasis has now become essential to obtain data that will help in providing maintenance care and establishing long-term prognosis since it is evident that many pitfalls remain, and that the most obvious of these relate to the necessity of continuing steroid therapy for protracted periods of time.

\section{THYMECTOMY}

In this connection, it seems pertinent to review the possible influence of thymectomy on the late results after homotransplantation. It was noted earlier that eight of the first patients received preliminary thymectomy (15) in preparation for transplantation. This adjuvant procedure, performed through a sternum-splitting incision in patients with terminal uremia, proved to have a high technical risk. In addition, the early course after homotransplantation did not seem to be different from that observed in patients who did not have the added operation. Consequently, the use of this procedure was discontinued until long-term follow-up could be obtained on those patients for whom it had already been employed.

The inefficacy of thymectomy in preventing or temporing early rejection does not, of course, rule out the possibility of later benefit. Theoretically, this might, in fact, be consistent with what has been learned of thymic function by Miller $(49,50)$ and others from experiments on lower animals. It might be anticipated that the reactivity of immunologically competent cells already present throughout the body would not be affected by thymectomy so that the intensity and immediacy of early rejection would not be altered by this operation. If, however, the thymus is in some way necessary for continued replication of immunologically specific strains of host cells, these cell lines might be expected ultimately to undergo drastic reduction under the combined influence of unrelenting immunosuppressive therapy and the continuous antigen loading provided by the homograft.

Four (LD 1, 2, 3, and 6) of the original eight patients are still alive from 14 to 18 months after homotransplantation. All have normal renal function. In each instance maintenance therapy with prednisone was discontinued on or before 270 days, and in one (LD 3) it was never required. Both in those who did (LD 1 and 2) and those who did not (LD 3 and 6) have a serious rejection crisis, there has been no evidence whatsoever of late deterioration of renal function.

Consideration of the fate of the unsuccessfully treated four patients who had removal of the thymus might be important in assessing the possible role of this procedure in the long-term outlook. Unfortunately, this does not seem to be the case since all of the patients either died in the early postoperative period (LD 5 and 11) or at a later time from complications other than renal failure (LD 4 and 9). The position could be taken that thymectomy did not receive a fair test in any of the latter four patients. 
There is at present insufficient information to permit even tentative opinions about the potential delayed value of thymic excision after homotransplantation. Most of the canine experimental work designed to test the influence of this operation has focused upon earlier postoperative events, partly out of necessity since the yield of chronic survivors in dogs is much less than after clinical renal homotransplantation. In our own laboratories, survival for as long as a year has not been achieved in any animal initially treated with thymectomy. The dogs with greatest longevity, including two that have not required immunosuppressive therapy for almost a year (3), did not have thymectomy.

Nevertheless, the question of whether or not to remove the thymus gland is by no means settled. Indeed, the observations cited above from experience with the earlier human cases emphasizes the urgent need for further clinical evaluation of this procedure. With the small group of patients now under study, it will be impossible to determine if thymectomy contributed to the ease of late management and to the rapidity with which steroids could be discontinued altogether since in each of the four cases the donor-recipient genetic relationships were highly favorable, and the outcome may have been the same with or without removal of the thymus.

\section{SUMMARY}

Fifty-one patients were treated with homografts obtained from both related and nonrelated volunteer donors in the interval from November 24, 1962, to February 10, 1964. Thirty-three of the 51 patients lived for 4 or more months postoperatively, and 30 of these are still living on June 10, 1964.

The three deaths which occurred after 4 months were due to a combination of gastrointestinal hemorrhage and sepsis in one; to a cerebrovascular accident of undetermined etiology in the second; and to uncontrolled late rejection in the third, which was first diagnosed 229 days after operation, 66 days before death. The two homografts examined at autopsy after 207 and 295 days were both enlarged and showed glomerular hypertrophy, tubular atrophy, mild cellular infiltrations, marked interstitial fibrosis, and destruction of peritubular capillaries. The case that died in uncontrolled rejection also showed interstitial edema and a spectrum of vascular lesions.

Late nonfatal rejection was observed in five other cases 112 to 300 days postoperatively. In all these cases, and in the unsuccessfully treated one as well, certain consistent features were present. There had always been a preceding alteration in steroid dose, prednisone having been discontinued in five of the six patients from 16 to 154 days previously. Progress of the rejection was slow, and the proper diagnosis depended most strongly upon demonstration of a gradual fall in creatinine clearance. Elevations in blood pressure, transplant wound tenderness, fluid accumulation, alopecia, polyarthritis, fever, malaise, and anorexia were all observed. Azotemia was a late finding.

The diagnosis of late rejection is one of exclusion. Pyelonephritis, vascular anastomotic failure, and ureteral obstruction are first ruled out. The last possibility is a particularly important one since 4 of the 33 patients who lived for 4 months or longer have been shown to have partial ureteral obstruction which required secondary repair. In one case, there was strong evidence that the stricture resulted from healing of an earlier ureteral rejection.

If diagnosed promptly, late homograft rejection can be reversed. The crucial step in the treatment of rejection is the resumption or increase of steroid dosage. In addition, local irradiation to the graft and intravenous actinomycin $\mathrm{C}$ are both of use as emergency therapy.

The chronic administration of azathioprine has thus far appeared to be very well-tolerated by those patients who are receiving only this drug, although its ultimate toxicity will take years 
to determine. The superimposition of steroid therapy, in those patients whose homograft function cannot be otherwise maintained, adds a serious risk. Gastrointestinal hemorrhages, infections, aseptic bone necrosis, potentiation of hypertension, and severe obesity have all been observed.

The course of five patients who received preliminary thymectomy and who survived more than 4 months is compared to that of the other recipients who did not receive this additional operation. One of the patients who had thymic excision died after 207 days of nonrenal complications. The other four had steroids discontinued in 9 months or less, and none have had any evidence of delayed rejection 14 to 18 months after operation. The 6 examples of late rejection all occurred in the other 28 long-surviving patients who did not have removal of the thymus gland. The possible role of thymectomy in influencing these late events remains to be determined.

Renal function ranged from adequate to essentially normal levels in all patients who survived longer than 4 months, except the one who died of uncontrolled late rejection. In four cases, in which late renal function was tested at a time when rejection was not present, the results in paired donors and recipients were almost identical, suggesting hypertrophy in the homograft as well as in the donor's residual kidney.

These results indicate that considerably more than half the patients who are treated with renal homotransplantation can be brought into a chronic stage, even when the statistics are unfavorably altered by the use of a substantial number of nonrelated donors as was the case in the present series. The data also indicate that overoptimism must be avoided in assessing the future role of this form of therapy since it is quite evident that many adverse factors still exist in the residual group of living patients, and that life-threatening late complications are going to be common. These include toxicity from drugs, especially if indefinite steroid therapy is required; late rejection; urologic complications; and subtle subclinical progression of pathologic alterations in the homograft.

\section{SUMMARIO IN INTERLINGUA}

Cinquanta-un patientes esseva tractate con homograffos renal ab donatores voluntari. Le plus recente del operationes esseva effectuate 4 menses retro. Trenta superviventes es accessibile pro observationes catamnestic de un duration de inter 4 e $18 \frac{1}{2}$ menses. Le melior resultatos esseva obtenite in le uso de geneticamente relationate donatores. Tres patientes, altere que le 30 mentionate, superviveva 4 menses o plus.

Un numero de importante complicationes tardive esseva observate. Sex patientes manifestava episodios de rejection tardive inter 4 e 10 menses post le operation, e in un de istes le processo non poteva esser arrestate. In omne iste casos, le rejection sequeva le reduction o suspension del medication steroidee. Le constatationes pathologic in homograffos recovrate longemente post le transplantation es revistate a base de materiales in le presente serie e de datos trovate in le litteratura. Le anormalitates characteristic de multe homograffos pare consister de fibrosis interstitial, de destruction de capillares peritubular, e de atrophia tubular, augmentate per un spectro de necrotic e proliferative lesiones afficiente arterias de varie dimensiones.

Complicationes altere que rejection pote devenir hasardose pro le patiente longemente post le homotransplantation. Obstruction ureteral ha essite incontrate e corrigite chirurgicamente in 4 patientes, e in un de istes le constrictura ureteral pareva esser un consequentia tardive de un processo de rejection. Altere invalidante o potentialmente mortal complicationes tardive esseva observate in patientes requirente chronic therapia steroidee. Istos includeva hemorrhagia gastrointestinal, aseptic necrosis ossee, hypertension perdurative, e grados sever de obesitate. 
Rejection tardive o morbiditate tardive esseva frappantemente absente in 4 patientes qui habeva experientiate thymectomia preliminari e qui attingeva le stadio chronic de convalescentia. Nulle de iste patientes recipe steroides, e nulle ha monstrate evidentia de un rejection tardive. Es discutite le desiderato de un evalutation plus extense del rolo possibile de thymectomia como factor de influentia favorabile super le tardive curso clinic post homotransplantation.

\section{Acknowledgments}

This work was aided by grants A-6283, A 6344, HE 07735, AM 07772, AI 04152, and OG 27 from the United States Public Health Service.

\section{REFERENCES}

1. Murray JE. Human kidney transplant conference. Transplantation 1964;2:147.

2. Starzl TE, Marchioro TL, Rifkind D, Holmes JH, Rowlands DT, Waddell WR. Factors in successful renal transplantation. Surgery 1964;56:296. [PubMed: 14174749]

3. Starzl, TE. Transplantation of the Kidney. Philadelphia: W. B. Saunders Co.; 1965.

4. Hume DM, Magee JH, Prout GR Jr, Kauffman HM Jr, Cleveland RH, Bower JD, Lee HM, Kramer N. Studies of renal transplantation in men. Ann. NY Acad. Sci. In press.

5. Hamburger J, Crosnier J, Dormont J. Observations in patients with a well tolerated homotransplanted kidney: possibility of a new secondary disease. Ann. NY Acad. Sci. In press.

6. Hamburger J, Vaysse J, Crosnier J, Anvent J, Dormont J. Résultats de quatorze transplantations rénales chez l'homme. Bull. Soc M'd. Hop. Paris 1963;114:225.

7. Murray JE, Merrill JP, Harrison JH, Wilson RE, Dammin GJ. Prolonged survival of human kidney homografts with immunosuppressive drug therapy. New Eng. J. Med 1963;268:1315. [PubMed: 13936775]

8. Woodruff MFA, Robson JS, Nolan B, Lambiek, Wilson TI, Clark JG. Homotransplantation of the kidney. Lancet 1963;2:675. [PubMed: 14052033]

9. Starzl TE, Marchioro TL, Waddell WR. The reversal of rejection in human renal homografts with subsequent development of homograft tolerance. Surg. Gynec. Obstet 1963;117:385. [PubMed: 14065716]

10. Goodwin WE, Kaufman JJ, Mims MM, Turner RD, Glassock R, Goldman R, Maxwell NM. Human renal transplantation. I. Clinical experience with 6 cases of renal homotransplantation. J. Urol 1963;89:13. [PubMed: 13949129]

11. Küss R, Legrain M, Camey M, Désarmenine J, Mathé G, Nedey R, Vourc'h C. Homotransplantation rénale chez l'homme. Mem. Acad. Chir. (Paris) 1961;87:183. [PubMed: 13755397]

12. Calne RY, Alexandre GPJ, Murray JE. A Study of the effects of drugs in prolonging survival of homologous renal transplants in dogs. Ann. NY Acad. Sci 1962;99:743. [PubMed: 14017936]

13. Shackman R, Dempster WJ, Wrong OM. Kidney transplantation in the human. Brit. J. Urol 1963;35:222. [PubMed: 14063906]

14. Hume DH, Magee JH, Kauffman HM Jr, Rittenbury MS, Prout GR Jr. Renal transplantation in man in modified recipients. Ann. Surg 1963;158:608. [PubMed: 14067508]

15. Starzl TE, Marchioro TL, Talmage DW, Waddell WR. Splenectomy and thymectomy in human renal homotransplantation. Proc. Soc. Exp. Biol. Med 1963;113:929. [PubMed: 14073145]

16. Wilson MC, Wilson CL, Mendelsohn EA, Crow NE. Improved excretory urograms by use of second injection of contrast medium. J. Urol 1962;87:1010. [PubMed: 14007393]

17. Winter, CC. Radioiostope renography. Baltimore: Williams \& Wilkins Company; 1963.

18. Collins JJ, Plzaak LF, Tamvacopoulos SK, Wilson RE. Serial renograms after kidney transplantation in man. Surg. Forum 1963;14:217. [PubMed: 14064524]

19. Murray JE, Merrill JP, Dammin GJ, Wilson RE, Hager EB. Kidney transplantation. Transplantation 1964;2:161.

20. Porter, KA. Pathological changes in transplanted kidneys. In: Starzl, TE., editor. Transplantation of the Kidney. Philadelphia: W. B. Saunders Company; 1965. 
21. Porter KA, Marchioro TL, Owen K, Peart WS, Starzl TE. Ureteric at pelvic lesions in human renal homotransplants. In preparation.

22. Porter KA, Thomson WB, Owen K, Kenyon JR, Mowbray JE, Peart WS. Obliterative vascular changes in 4 human kidney homotransplants. Brit. Med. J 1963;2:639. [PubMed: 14046168]

23. Porter KA, Peart WS, Kenyon JR, Joseph NH, Koehn RJ, Calne RY. Rejection of kidney homotransplants. Ann. NY Acad Sci. In press.

24. McIlvanie SK, McCarthy JD. Hepatitis in association with prolonged 6-mercaptopurine therapy. Blood 1959;14:80. [PubMed: 13607581]

25. Einhorn M, Davidsohn I. Hepatotoxicity of mercaptopurine. JAMA 1964;188:802. [PubMed: 14132534]

26. Starzl TE, Marchioro TL, Rifkind DR, Dickinson TC, Stonington OG, Waddell WR. Technique of renal homotransplantation: experience with 42 cases. Arch. Surg. (Chicago) 1964;89:87.

27. Rifkind D, Marchioro TL, Waddell WR, Starzl TE. Infectious diseases associated with renal transplantation. II. Differential diagnosis and treatment. JAMA. In press.

28. Pierce JC, Varco RL. Effects of long term 6-mercaptopurine treatment upon kidney transplantation in dogs. Surgery 1963;54:124. [PubMed: 13943406]

29. McGane JD, Knight PR, Tomkiewica ZM, Alexandre GPJ, Murray JE. Analysis of the mechanism of drug induced tolerance in canine renal homotransplants. Surg. Forum 1963;14:210. [PubMed: 14064522]

30. Zukoski CF, Callaway JM. Adult tolerance induced by 6-methyl mercaptopurine to canine renal homografts. Nature 1963;198:706. [PubMed: 14004077]

31. Woodruff MFA. Postpartum induction of tolerance to homologous skin in rats. Ann. NY Acad. Sci 1957;64:792. [PubMed: 13411918]

32. Merrill JP, Murray JE, Harrison JH, Friedman EA, Dealy JB Jr, Dammin GJ. Successful homotransplantation of the kidney between non-identical twins. New Eng. J. Med 1960;262:1251.

33. Murray, JE. Personal communication. 1964 Apr 30.

34. Goodwin WE, Martin DC. Transplantation of the kidney, Spring 1963. Urol. Survey 1964;13:229.

35. Antoine B. Renal transplantation. Transplantation 1964;2:156.

36. Shackman R. Renal transplantation. Transplantation 1964;2:160.

37. Hamburger, J. Personal communication. 1964 May 10.

38. Dempster, WJ. Personal communication. 1964 May 8.

39. Küss R, Legrain M, Mathé G, Nedey R, Camey M. Homotransplantation rénale chez l'homme hors de tout lien de parenté. Survie juqu'au dix-septiéme mois. Rev. Franc Étud. Clin. Biol 1962;7:1048.

40. Woodruff, MFA.; Robson, JS. Personal communication. 1964 May 11.

41. Dempster WJ, Harrison J, Shackman R. In press.

42. Murray JE, Merrill JP, Harrison JH. Kidney transplantation between 7 pairs of identical twins. Ann. Surg 1958;148:343. [PubMed: 13571912]

43. Krieg AF, Bolande RP, Holden WD, Hubay CA, Persky L. Membranous glomerulonephritis occurring in a human renal homograft. Amer. J. Clin. Path 1960;2:155. [PubMed: 14411991]

44. Githens JA. Unpublished observation.

45. Küss R, Legrain M, Mathé G. Renal transplantation. Transplantation 1964;2:159.

46. Rifkind D, Starzl TE, Marchioro TL, Waddell WR, Rowlands DT, Hill RB. Transplantation pneumonia. JAMA. In press.

47. Hume, DM. Personal communication. 1964 Apr 2.

48. Kolff, WJ. Personal communication. 1964 Jun 1.

49. Miller JFAP. Immunological significance of the thymus of the adult mouse. Nature (London) 1962;195:1318.

50. Miller JFAP. Immunity and the thymus. Lancet 1963;2:43. 


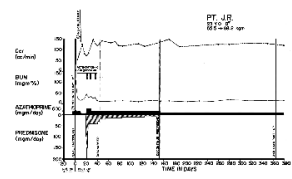

FIGURE 1.

Course of Patient LD 6, who received a homograft from his younger brother on April 17, 1963. Both were $\mathrm{O}$ blood type. Thymectomy was carried out 26 days before transplantation.

Splenectomy and right nephrectomy were performed at the same time as homotransplantation; the left kidney was removed 1 week later. A rejection crisis that occurred 18 days postoperatively was reversed with prednisone and actinomycin C. Steroids were discontinued after 5 months. The patient has normal renal function in June, 1964. 


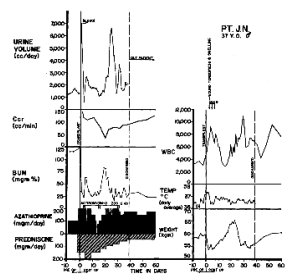

FIGURE 2.

Use of steroid pretreatment in a patient (LD 47) who received a homograft from his brother. Both were A blood type. Three days after operation, acute wound tenderness, hematuria, and anuria developed. Immediate relief followed the first dose (150 r) of transplant irradiation. Restoration of function was so rapid that creatinine clearance, which was based on a 24-hr urine collection, had only slight depression although early azotemia is evident. A second reversible rejection occurred at 14 days with recurrence of renal failure, weight gain, and temporary depression of white count. Note that steroids completely masked the fever of rejection. The patient has normal renal function in June, 1964, more than 150 days after operation (see Table 1). 


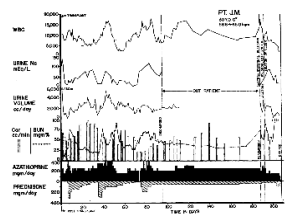

FIGURE 3.

Course of a patient (LD 9) who had 3 separate early rejection crises beginning after 5, 34, and 71 days. Note decline of sodium excretion on each occasion and reversal of pattern with increases of prednisone doses. He died 10 days after emergency operative treatment of a bleeding duodenal ulcer. At autopsy, multiple fungal brain abscesses were also found as well as pneumonia. Total survival was 207 days. This patient had a thymectomy 85 days before homotransplantation. 


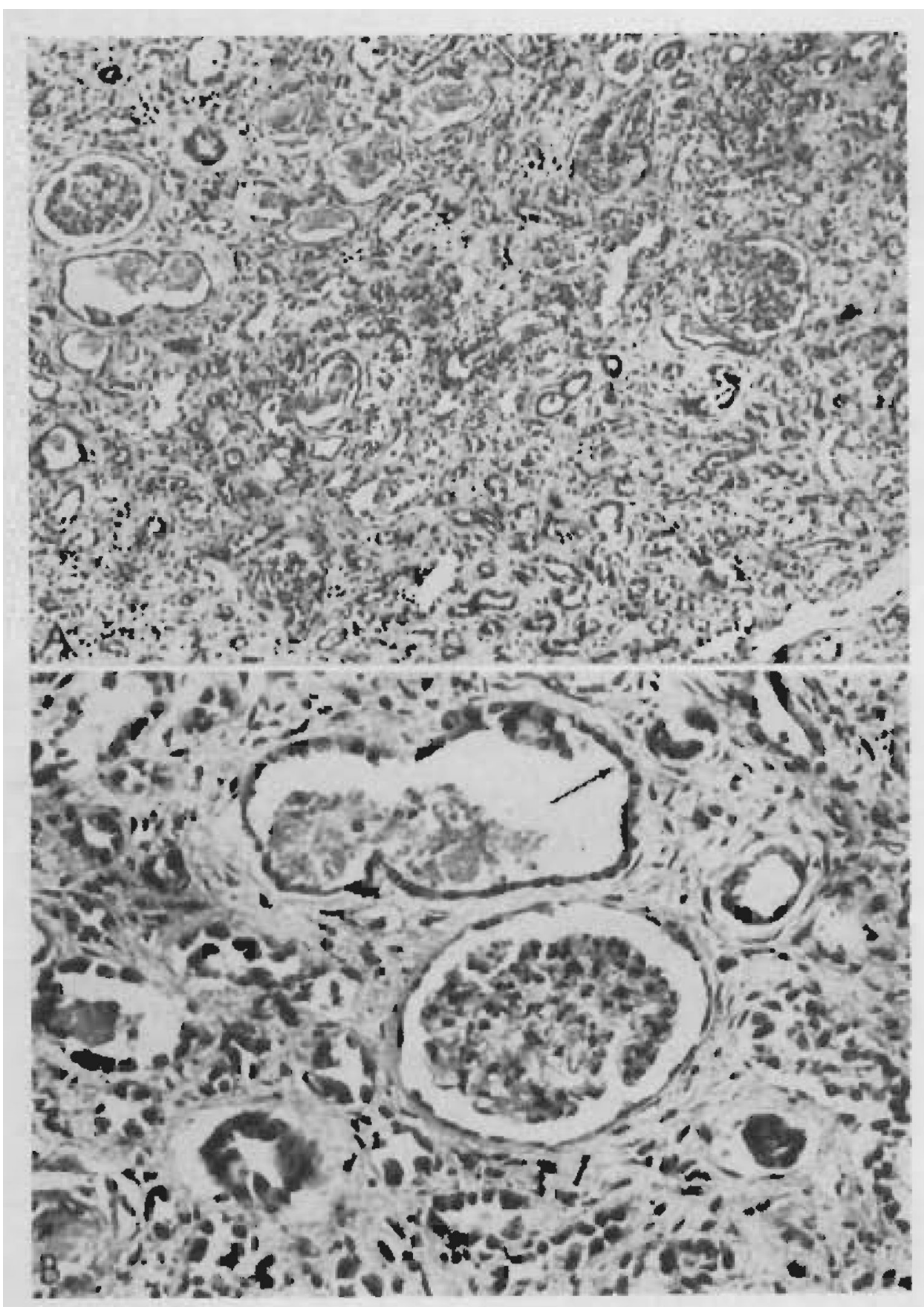

FIGURE 4.

Two photomicrographs of the renal homotransplant from Patient LD 9 who died at 207 days. Rejection episodes at 5,34, and 71 days had been successfully reversed. A. There is widespread tubular atrophy and interstitial fibrosis, but very little cellular infiltration. Hematoxylin and eosin stain, $\times 150$. B. The absence of peritubular capillaries should be noted. A dilated atrophic tubule (arrow) is lined by flattened regenerating epithelium. Hematoxylin and eosin stain, $\times$ 250 . 


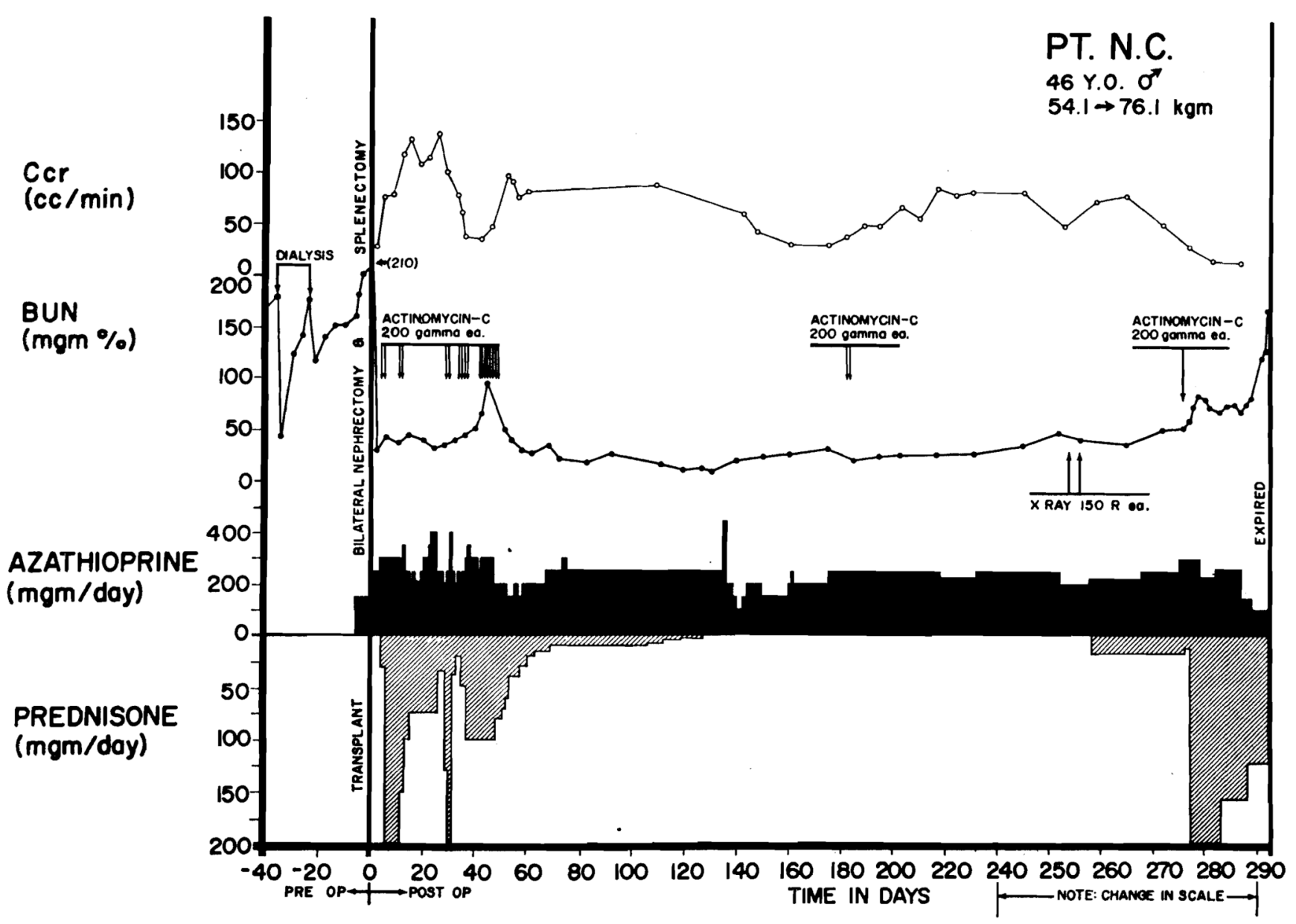

FIGURE 5.

Course of a patient (LD 10) who died of late rejection 295 days after homotransplantation. The donor was unrelated. The diagnosis of rejection was first made at 229 days, but effective adjustments in therapy were not made. Note the transient fall in blood urea nitrogen after local irradiation of the transplant. Vigorous therapy was withheld for too long, and uremia became progressive and irreversible. Terminally, he had multiple pulmonary emboli. 


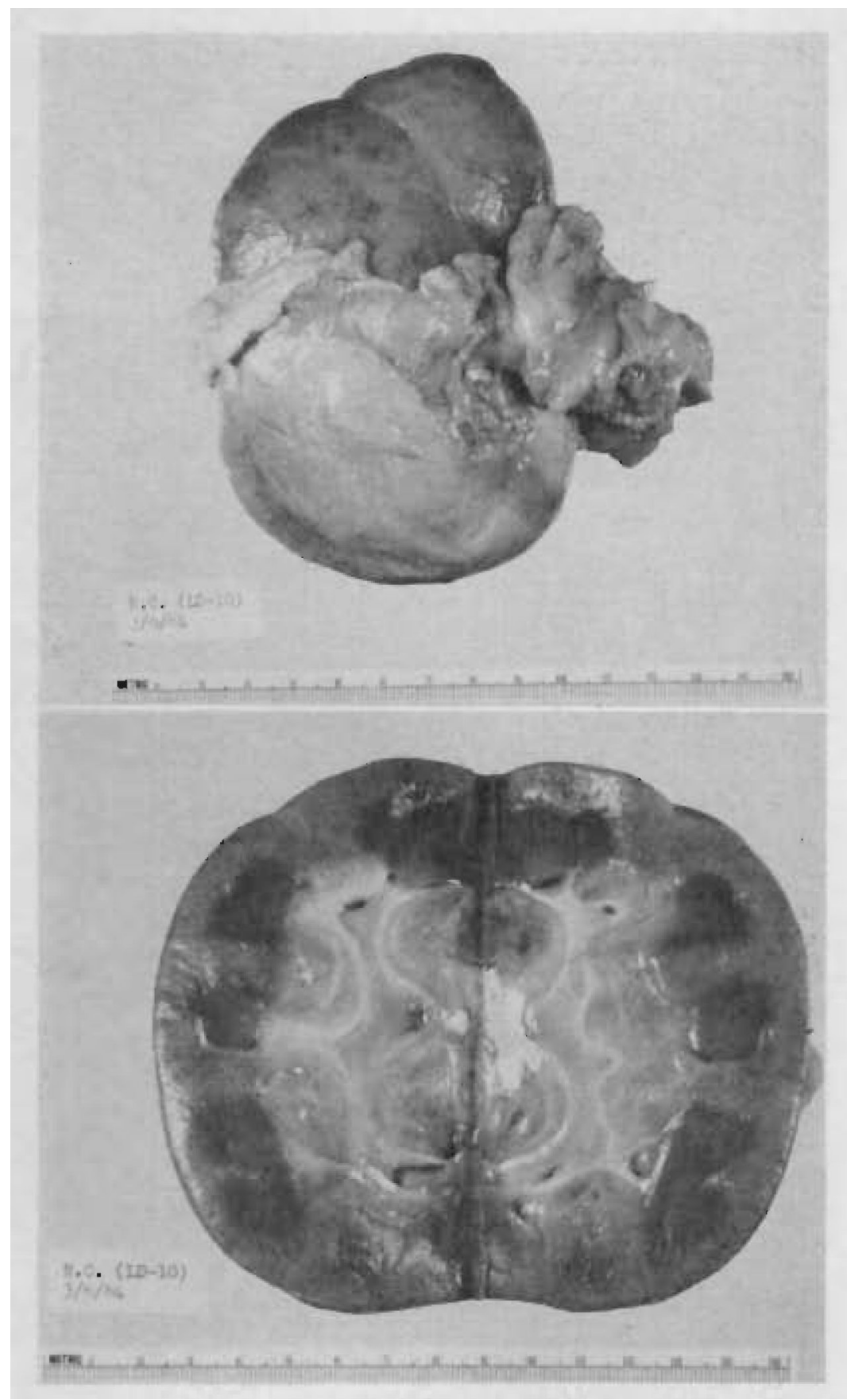

FIGURE 6.

Homograft from Patient LD 10, as seen at autopsy 295 days after operation. Upper photograph: the capsule is partly stripped, showing the smooth subcapsular surface with occasional tiny petechial hemorrhages and persistent fetal lobation. Lower photograph: the cut cortex bulges over the capsule, and a few pinpoint cortical hemorrhages are present. Otherwise, the appearance is normal. Weight was $260 \mathrm{~g}$. 


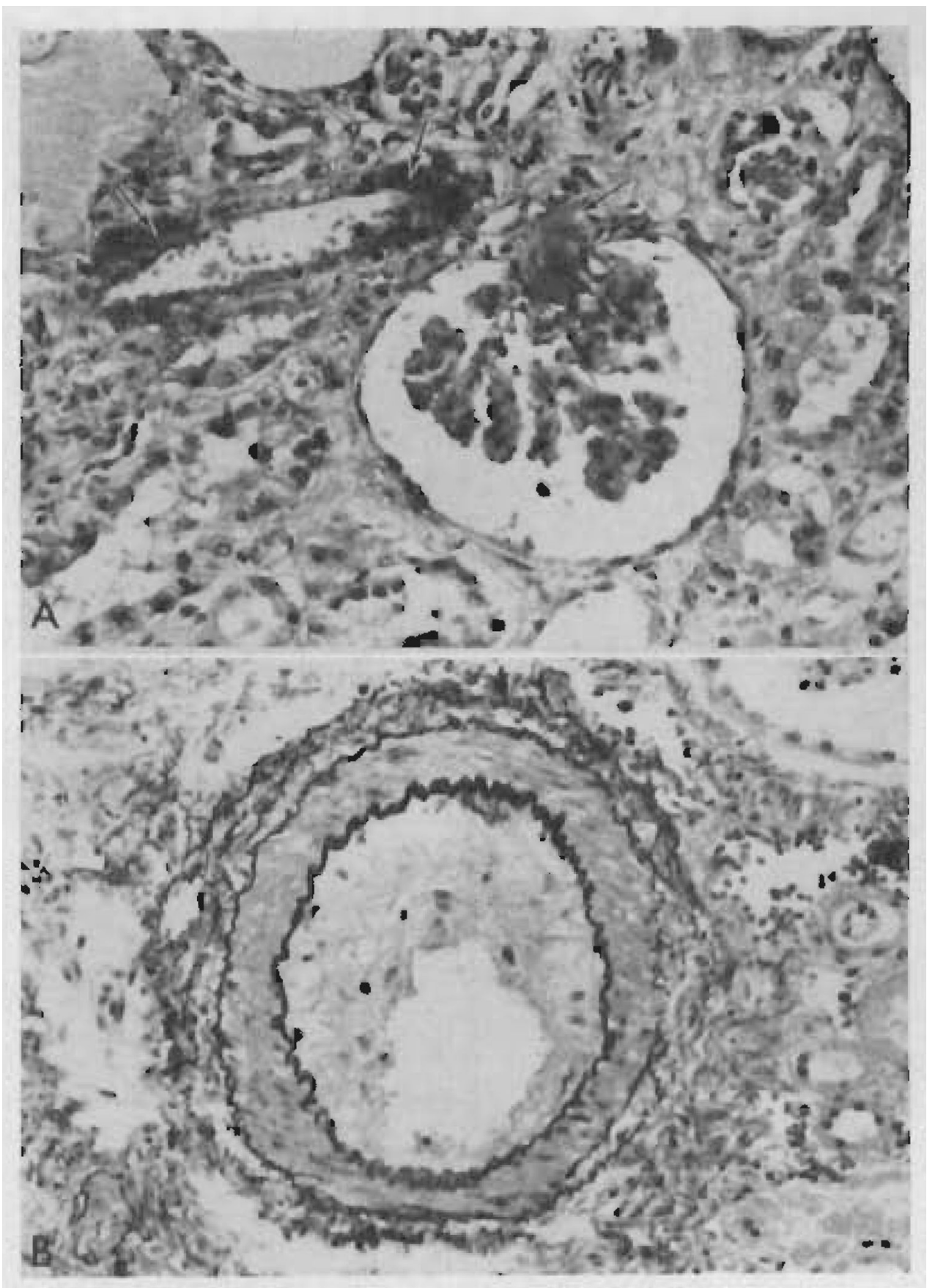

FIGURE 7.

Two photomicrographs of the renal homotransplant from Patient LD 10 who died at 295 days in a rejection phase. A. There is fibrinoid necrosis (arrow) of part of the wall of an afferent arteriole with extension of the process into the glomerular tuft capillaries. The tubules are atrophic and the interstitium shows fibrosis and some edema. Hematoxylin and eosin stain, $x$ 350. B. An arcuate artery shows marked fibrous intimal thickening. Elastic/van Gieson stain, $\times 200$. 


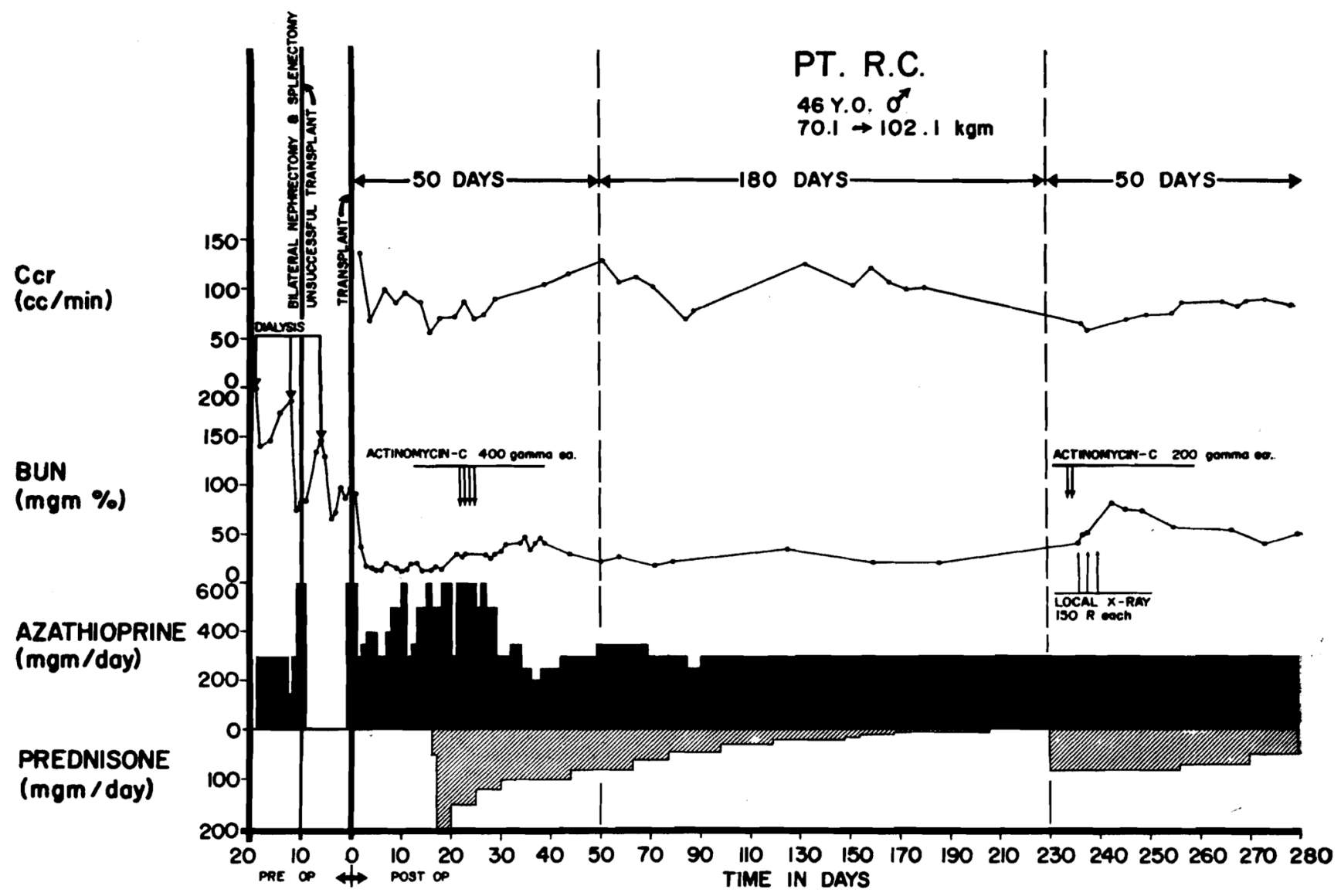

FIGURE 8.

Severe delayed rejection in a patient (LD 23) who received a homograft from an unrelated donor. Note rises in blood urea nitrogen and declines in creatinine clearance after discontinuance of steroid therapy. Creatinine clearance began to rise after institution of emergency therapy, although the azotemia became temporarily worse. Further improvement in renal function continued after preparation of this graph; during the last 2 weeks of May, 1964, and the first week of June, 1964, creatinine clearances averaged $85 \mathrm{ml} / \mathrm{min}$ and blood urea nitrogen averaged 32 . 


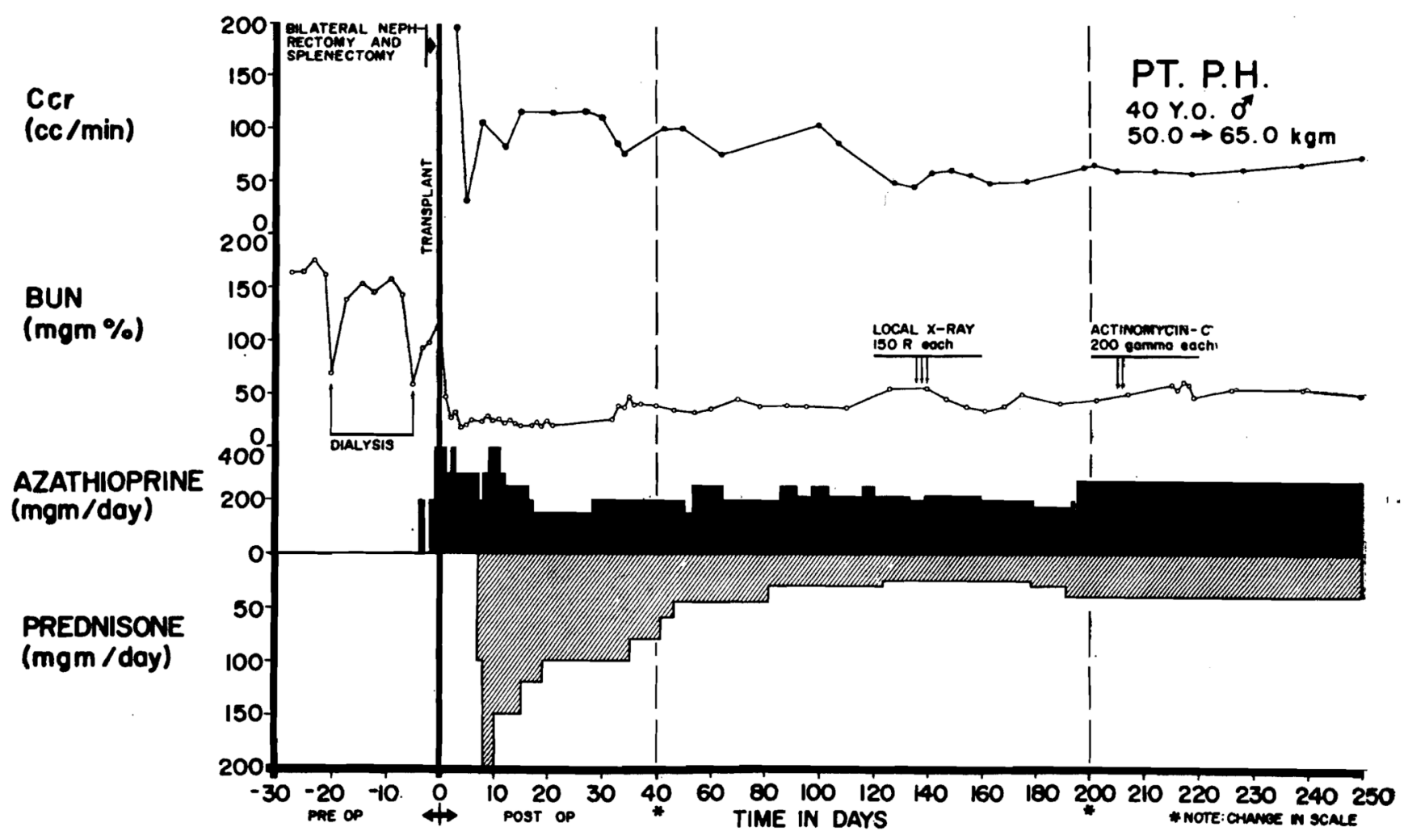

FIGURE 9.

Delayed rejection in a patient (LD 30) who received a homograft from an unrelated donor. Deterioration of renal function occurred after reduction of prednisone from 45 to $30 \mathrm{mg} / \mathrm{day}$. Note transient improvement after a course of local transplant irradiation. Stable renal function was not obtained until the steroid doses had been returned to the previous higher levels. 


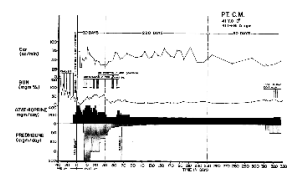

FIGURE 10.

Late rejection (Patient LD 12) appearing 300 days after homotransplantation and 6 months after discontinuance of steroid therapy. The homograft was provided by the patient's brother. 


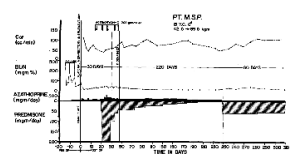

\section{FIGURE 11.}

Delayed rejection in a 15-year-old boy (LD 13) who received a kidney from his mother. After steroids were stopped, there was a gradual fall of creatinine clearance. The patient had no symptoms. Note gradual restoration of creatinine clearance after the institution of $60 \mathrm{mg} / \mathrm{day}$ prednisone. 


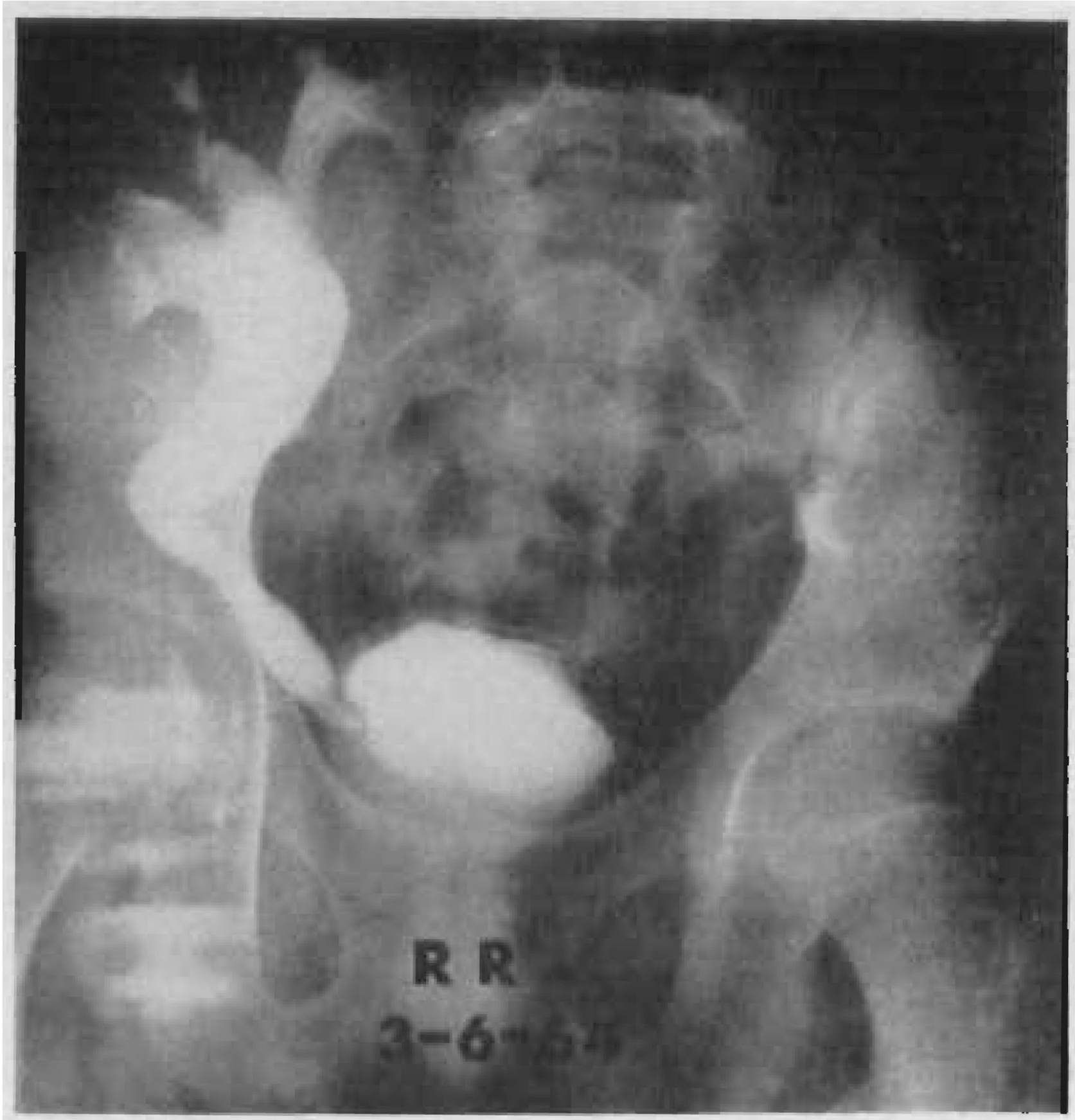

FIGURE 12.

Intravenous pyelogram 4 months after homotransplantation in Patient LD 39. A contrast intensification technique was used. Note the partial obstruction at the ureteroneocystostomy. At a subsequent secondary operation, the proximal ureter of the homograft was anastomosed to the patient's own right ureter, which had not been removed at the time of the original right nephrectomy. The result was satisfactory. 


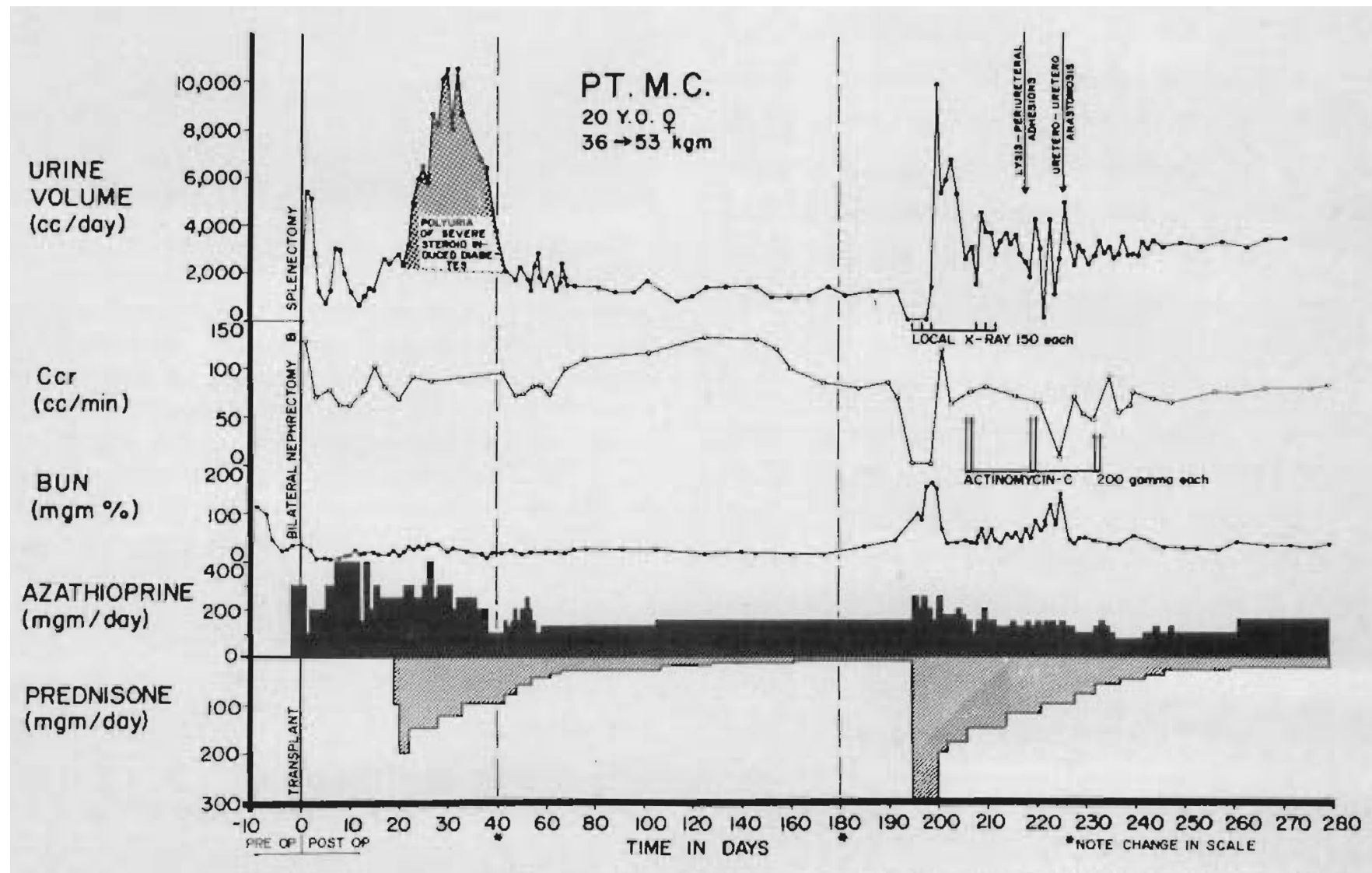

FIGURE 13.

Course of a 21-year-old woman, LD 27, who received a homograft from an unrelated male donor. Both were of A blood type. Early postoperative rejection was very mild. After 190 days, she suddenly became anuric, subsequently alternating with bouts of brisk diuresis. Although she was treated as an acute rejection, it was subsequently demonstrated that she had severe midureteric stricture that was thought to be a consequence of late healing that followed a previous rejection. After correction of the mechanical difficulty she has been well. 

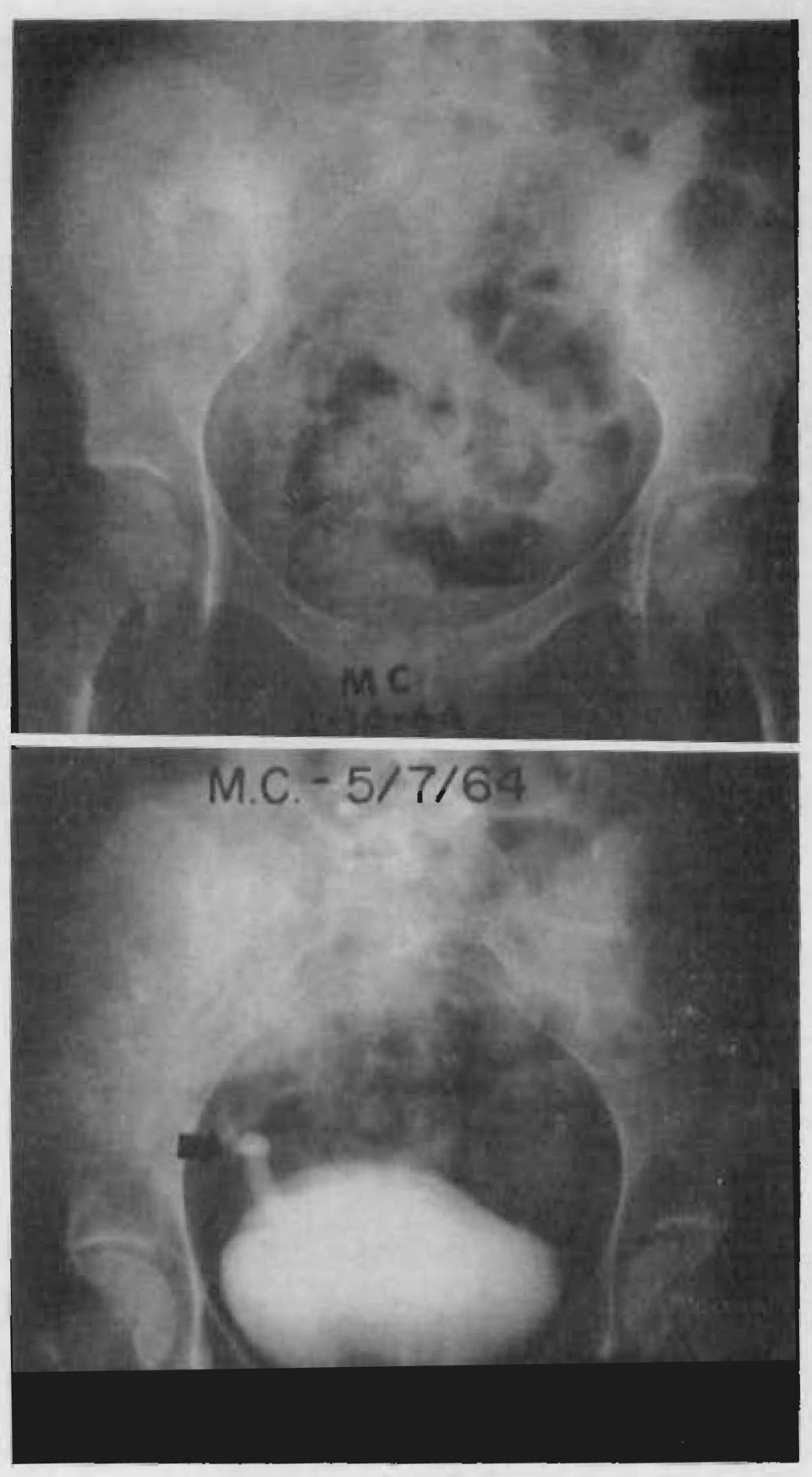

FIGURE 14.

Intravenous pyelograms of same case (LD 27) shown in Figure 13. Top photograph: intravenous pyelogram showing high-grade obstruction of the homograft midureter. Bottom photograph: appearance after resection of the stenosed ureter and re-anastomosis to the patient's own ipsilateral ureter. The anastomotic site is shown with an arrow. The somewhat dilated distal portion is the patient's own ureter, which had previously been demonstrated to have reflux. 


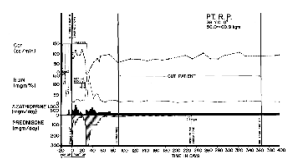

FIGURE 15.

Chronic course of Patient LD 2 who received a homotransplantation from his sister in January, 1963. The patient was of A blood type. His sister was B. Note progressive improvement in creatinine clearance, starting after 3 postoperative months. Prednisone was discontinued after 230 days. The patient had a preliminary thymectomy. 


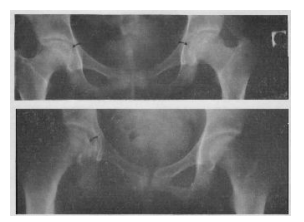

FIGURE 16.

Appearance of aspetic necrosis of the femoral head in two young women after transplantation. Both were on prednisone therapy at the time of this delayed complication. Upper photograph: Patient LD 22. Lower photograph: Patient LD 50. 


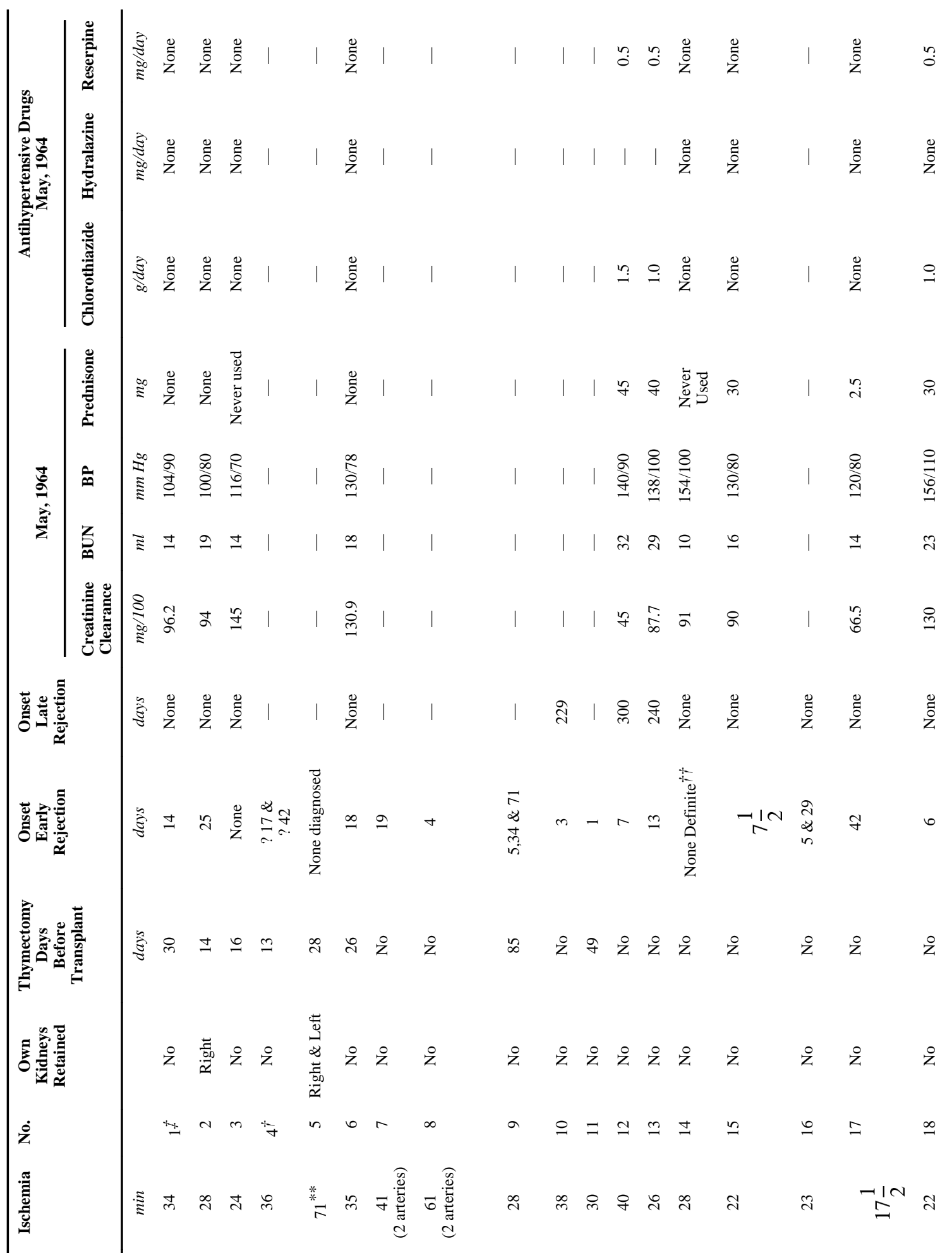




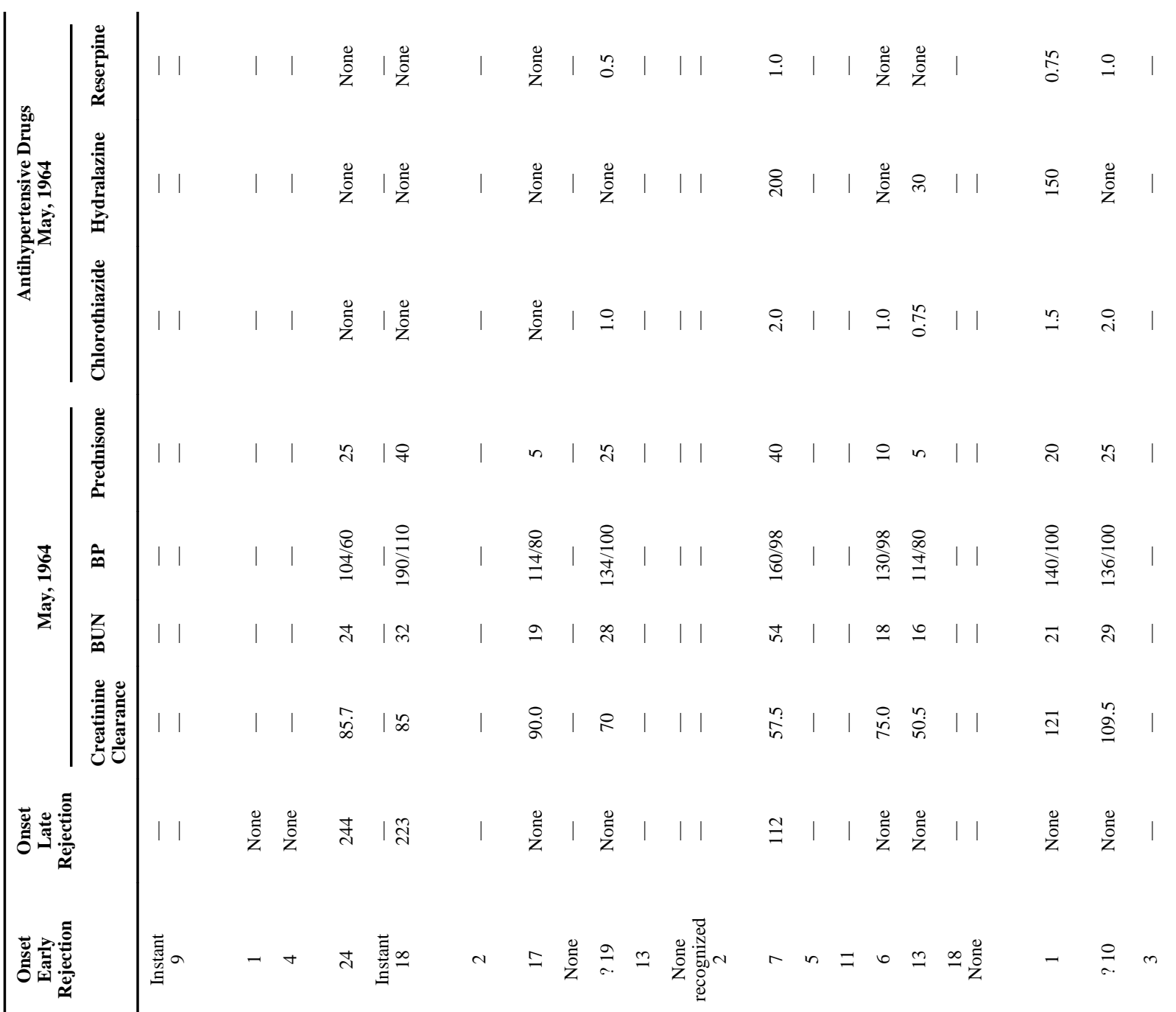

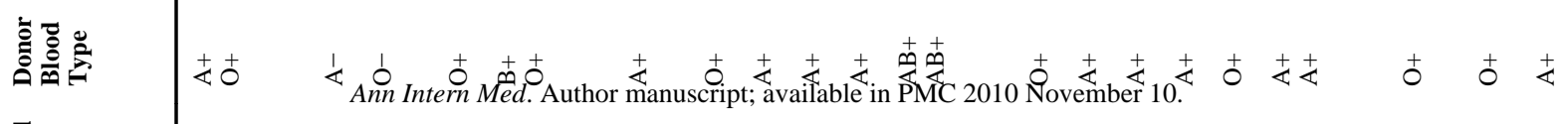

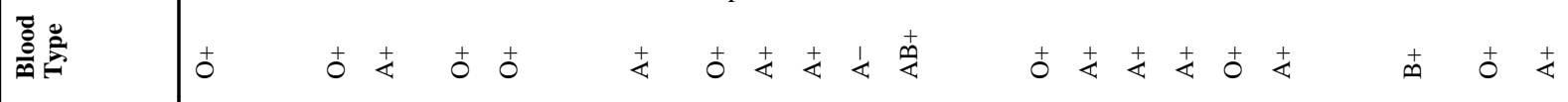

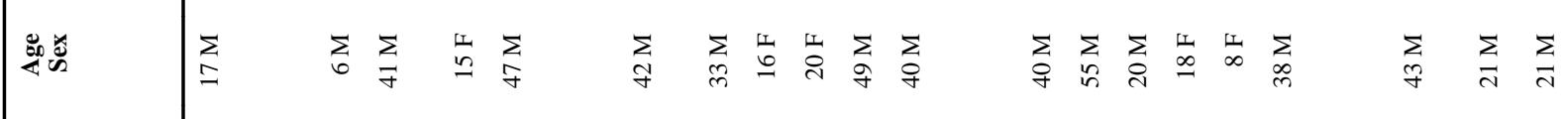

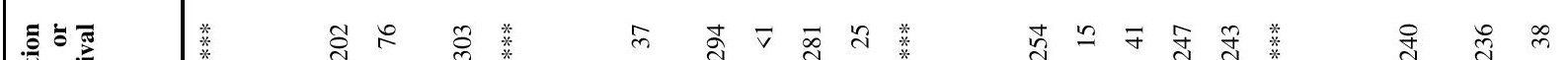




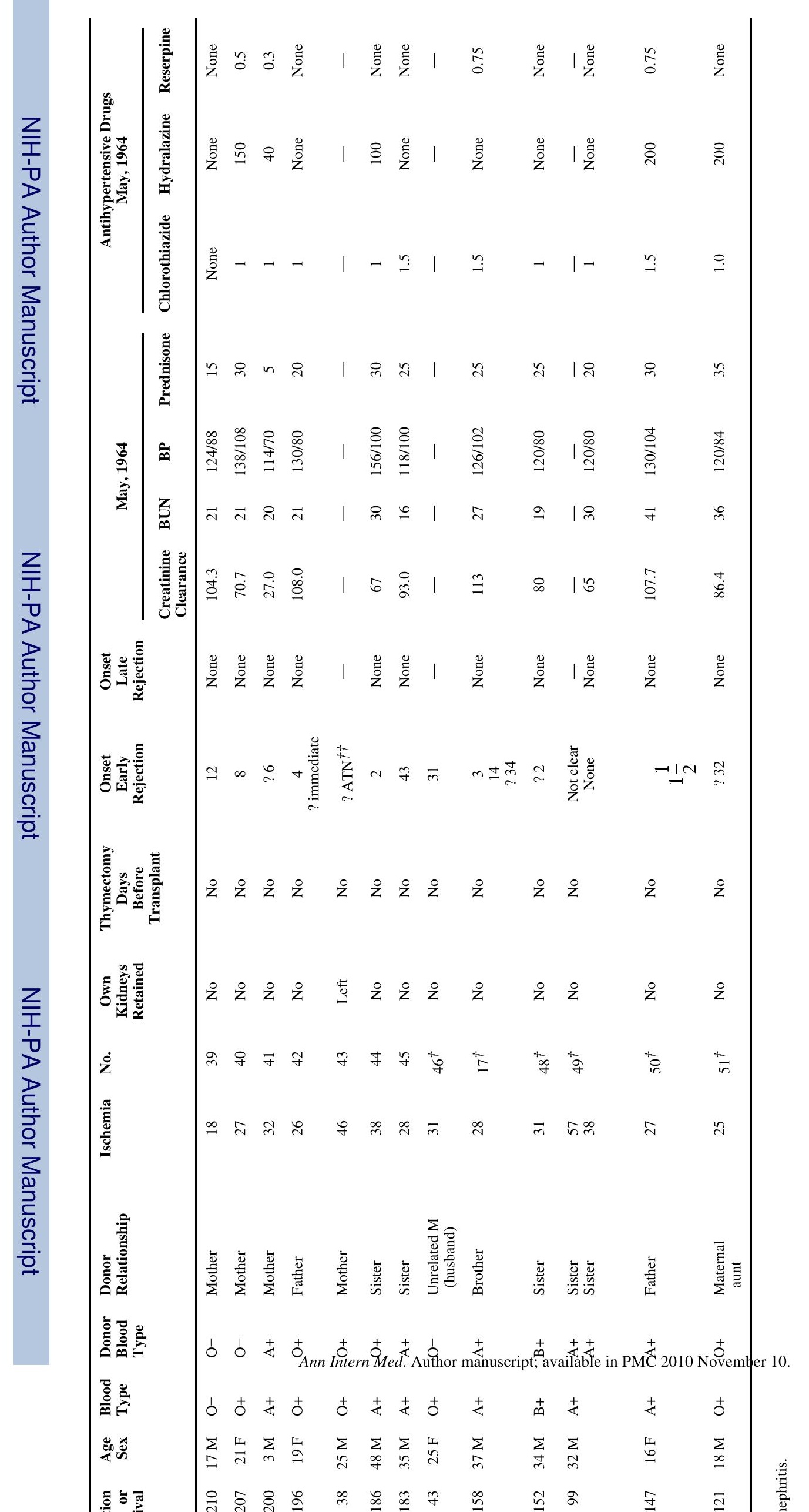




\section{TABLE 2}

Mortality and Survival in Patients Who Received Renal Homotransplants 4 Months or Longer Ago (November, 1962, to February, 1964)*

\begin{tabular}{lr}
\hline Total number of patients & 51 \\
Died within the first 4 months & 18 \\
Survived for at least 4 months & 33 \\
Died after 4 months & 3 \\
Survived to date (June, 1964) & 30 \\
Total transplanted 1 year ago or longer & 12 \\
Survived for 1 year or longer (longest survivor 18 $\frac{1}{2}$ months) & 5 \\
\hline
\end{tabular}

* As of June 10, 1964. 
TABLE 3

Timing of Late Rejections

\begin{tabular}{cccl}
\hline LD No. & Days After Operation & Days After Steroid Change & Reversed \\
\hline 10 & 229 & 103 & No \\
12 & 300 & 154 & Yes \\
13 & 240 & 20 & Yes \\
22 & 244 & 60 & Yes \\
23 & 223 & 16 & Yes \\
30 & 112 & 30 & Yes \\
\hline
\end{tabular}

In all but LD 30, steroids had been stopped. For LD 30, the alteration consisted of reduction of prednisone from 45 to $30 \mathrm{mg} / \mathrm{day}$. 